\title{
Um modelo para previsão de renda utilizando esquemas de censura complexos
}

\author{
Danilo Clemente Coelho \\ DISSERTAÇÃO APRESENTADA \\ AO \\ INSTITUTO DE MATEMÁTICA E ESTATÍSTICA \\ DA \\ UNIVERSIDADE DE SÃO PAULO \\ PARA \\ OBTENÇÃO DO GRAU DE MESTRE \\ EM \\ CIÊNCIAS
}

Área de Concentração: Estatística

Orientador: Antonio Carlos Pedroso de Lima

São Paulo, novembro de 2006. 


\title{
Um modelo para previsão de renda utilizando esquemas de censura complexos
}

\author{
Este exemplar corresponde à redação final da \\ dissertação devidamente corrigida e defendida \\ por Danilo Clemente Coelho \\ e aprovada pela Comissão Julgadora
}

São Paulo, 22 de novembro de 2005.

\section{Banca examinadora:}

Prof. Dr. Antonio Carlos Pedroso de Lima (orientador) - IME/USP

Prof. Dr. Rinaldo Artes - IBMEC

Prof. Dr. Paulo Picchetti - FEA/USP 
"Everything should be made as simple as possible, but not simpler."

(Albert Einstein) 


\section{Agradecimentos}

Ao meu orientador, que me auxiliou a amadurecer a idéia, com imaginação, calma e confiança;

Aos meus chefes Júlio e Maira que apostaram na importância do meu mestrado antes mesmo de conhecerem meu trabalho;

Aos meus pais Denize e Renato e à minha noiva Cristiane que entenderam a necessidade das noites e fins de semanas na frente do computador;

A minha irmã Renata, que se privou do MSN por várias vezes;

Aos membros da banca examinadora, pelas horas dispendidas e sugestões valiosas;

Por último, a todos os amigos que me ajudaram com idéias, apoio e torcida. 


\section{Resumo}

Diversos modelos estatísticos vêm sendo desenvolvidos atualmente com o intuito de embasar decisões relativas a crédito. Uma informação de suma importância na análise e que por diversas vezes é de difícil obtenção, é a renda mensal do cliente. A determinação dessa característica tornase particularmente difícil num segmento específico da população que possui uma forte variabilidade mensal em sua renda ou possui ainda uma fonte informal de difícil comprovação, como por exemplo: aluguéis de casas, negócio próprios, renda pró-labore, aplicações financeiras, etc.

O presente trabalho teve por objetivo desenvolver uma metodologia capaz de inferir a renda de clientes no segmento citado acima, baseando-se em variáveis cadastrais e no comportamento dentro da instituição financeira. Para tanto foram adaptadas técnicas de regressão paramétrica e semi-paramétrica para variáveis censuradas e truncadas. Modelos não paramétricos foram utilizados para verificação do ajuste dos modelos. 


\section{Abstract}

Many statistical models have been developed in order to act as basis to credit related decisions. Knowing the clients' income is a valuable information for analysis, although this is not always possible. It is especially complicated in a specific segment of the population, which either has strong monthly income variability or has an informal incomes, such as home renting, private business, investing revenues etc.

This work assessed the development of a methodology capable of inferring the clients' income in the segment referred above, based on variables registered in cadastre and personal investing movements within financial institution. For in such a way, parametric and semi-parametric techniques for censored and truncated variables have been adapted. Non-parametric models have been applied for verification of the model fits. 


\section{Sumário}

1. Introdução.................................................................................................

1.1. Modelos aplicados à decisões de crédito................................................ 4

1.2. Objetivos e estrutura ......................................................................... 7

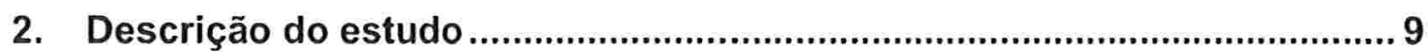

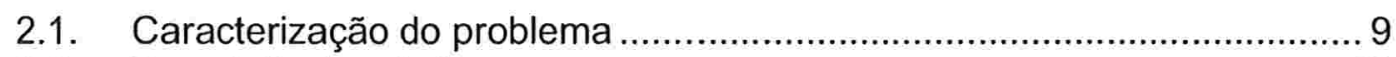

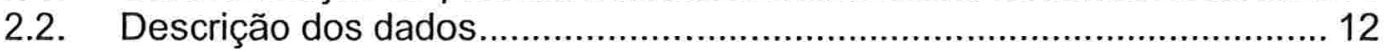

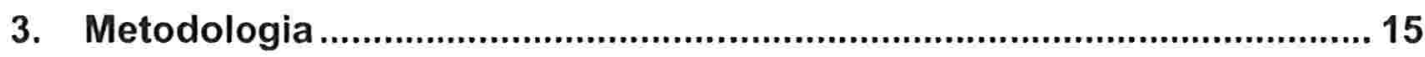

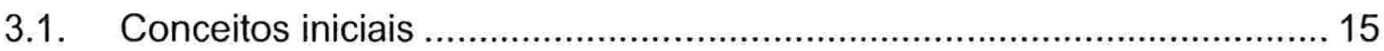

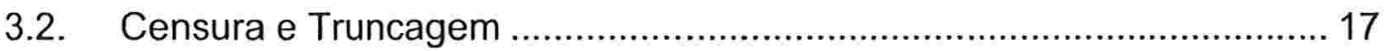

3.3. Modelos de sobrevivência.................................................................. 23

3.3.1. Modelos Não-Paramétricos _..................................................... 24

3.3.2. Modelos Paramétricos ................................................................ 25

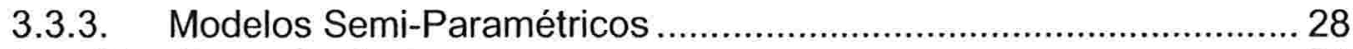

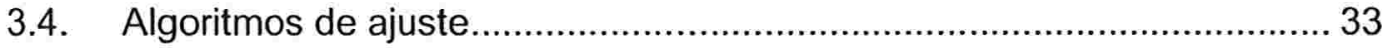

3.5. Adaptações da metodologia................................................................. 37

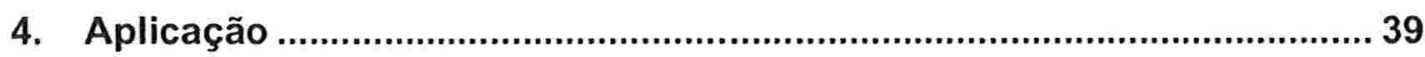

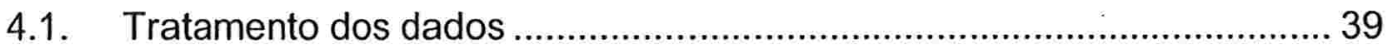

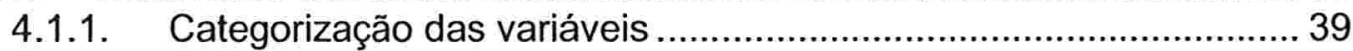

4.1.2. Consolidação longitudinal ........................................................... 40

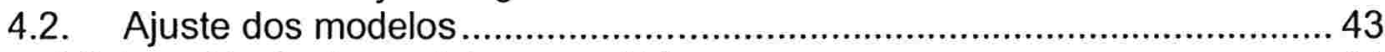

4.2.1. Ajuste do modelo paramétrico ................................................... 44

4.2.2. Ajuste do modelo semi-paramétrico............................................... 47

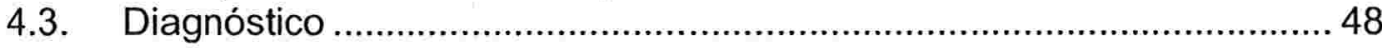

4.4. Comparação de desempenho ........................................................ 50

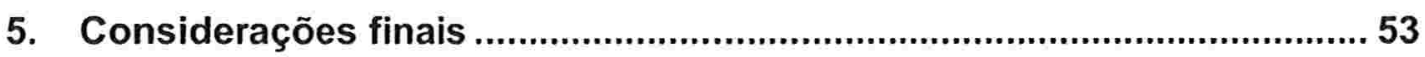

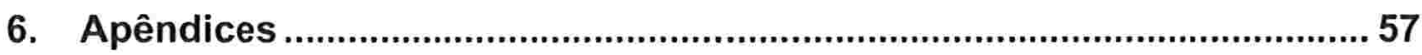

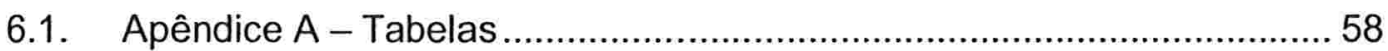

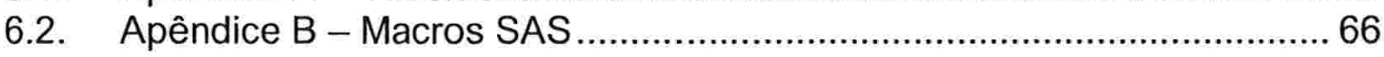

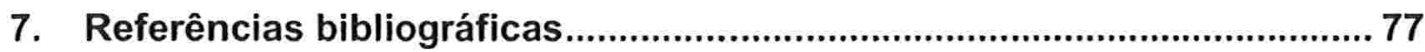




\section{Introdução}

Como reflexo da estabilização econômica, a economia brasileira vem apresentando uma mudança significativa no setor financeiro há alguns anos. À medida que os ganhos com a "ciranda financeira" deixaram de existir, os bancos voltaram a exercer sua principal função na sociedade, que é a intermediação financeira entre poupadores e tomadores de recursos. As carteiras de crédito nas instituições bancárias passaram a ser o principal produto e a desempenhar papel decisivo na rentabilidade do setor.

A concessão de crédito é de fundamental importância na economia de um pais, pois permite o diferimento de uma operação, ou seja, o bem é adquirido hoje, no entanto seu pagamento se dará posteriormente num momento mais propício para o tomador. Esse mecanismo injeta capital no mercado de modo que os consumidores sentem-se impelidos a comprar, propiciando assim um aumento do consumo e obrigando as empresas a produzirem mais. Por sua vez, as próprias empresas também tomam crédito, contornando uma eventual restrição orçamentária e possibilitando a compra de matéria-prima e equipamentos, mesmo que não existam recursos disponiveis no momento do pedido. Com o crescimento da empresa, essa se sente na obrigação de contratar mais funcionários, diminuindo o índice de desemprego da população o que aumenta o consumo, gerando um círculo de aquecimento da economia.

O governo federal vem desde janeiro de 2003 implantando diversas medidas para ampliar o acesso da população ao crédito ${ }^{1}$. Atualmente, cerca

\footnotetext{
${ }^{1}$ Medidas do Governo LULA para o Micro crédito. http://www.geranegocio.com.br/html/geral/p20-m.html\#lula. Acesso em 21 set. 2005.
} 
de $28 \%$ do PIB nacional vem de operações de financiamento ${ }^{2}$. Particularmente para pessoas físicas, um aumento consistente da demanda por crédito vem sendo notado, principalmente a partir de maio de 2004 devido à criação do crédito consignado em folha de pagamento (Figura 1.1) e a expectativa é que venha a crescer ainda mais ${ }^{3}$. Em 1996, 12,1\% do total de empréstimos foram destinados à pessoa física enquanto que em 2005 esse percentual já atingia $45,8 \%$. Especialistas afirmam que se a carteira continuar a crescer no mesmo ritmo, em 2007 o percentual destinado à pessoa física deverá igualar-se ao percentual destinado às pessoas jurídicas ${ }^{4}$.

Acompanhando essa crescente demanda, houve também um aumento significativo na oferta de crédito por parte de instituições financeiras que procuram sempre soluções inovadoras para disputar os melhores clientes e rentabilizar ao máximo sua carteira de ativos, sem comprometer o risco associado. Com esse objetivo, vários modelos estatísticos vêm sendo sugeridos para uma concessão de crédito mais eficiente e transparente, com o objetivo de minimizar as perdas decorridas de contratos feitos com clientes inadimplentes.

Além do controle da perda, também são necessários mecanismos de aumento da receita para máxima rentabilização da carteira. Faz-se assim importante a decisão de quanto dar de crédito. Para isso, instituições financeiras geralmente usam a informação de renda do cliente associada ao risco de inadimplência como forma de inferir sua capacidade de pagamento mensal. Porém, devido à política conservadora de algumas instituições ou até mesmo a uma desatualização cadastral, esse meio por diversas vezes subestima a capacidade real de pagamento do cliente, pois não são consideradas eventuais fontes de rendimento de comprovação duvidosa, como

\footnotetext{
${ }^{2}$ Financiamentos correspondem a 28,2\% do PIB. Valor Econômico, 24 ago. 2005.

${ }^{3}$ Comitê vai promover micro crédito no Brasil. PNUD Brasil, 27 abr. 2005.

http://www.pnud.org.br/administracao/reportagens/index.php?id01=1147\&lay=apu. Acesso em 21 set. 2005.

${ }^{4}$ O Show do Crediário. Revista Veja, 26 abr. 2006.
} 
por exemplo, aluguéis, mercado informal, renda pró-labore, renda do cônjuge, etc.

Esse efeito é ainda maior para um segmento de clientes composto em sua maioria por profissionais liberais, que em sua grande maioria pertencem ao mercado informal. Esses profissionais, além de ter uma renda mensal variável, não possuem uma fonte segura de comprovação de toda a sua renda efetiva.

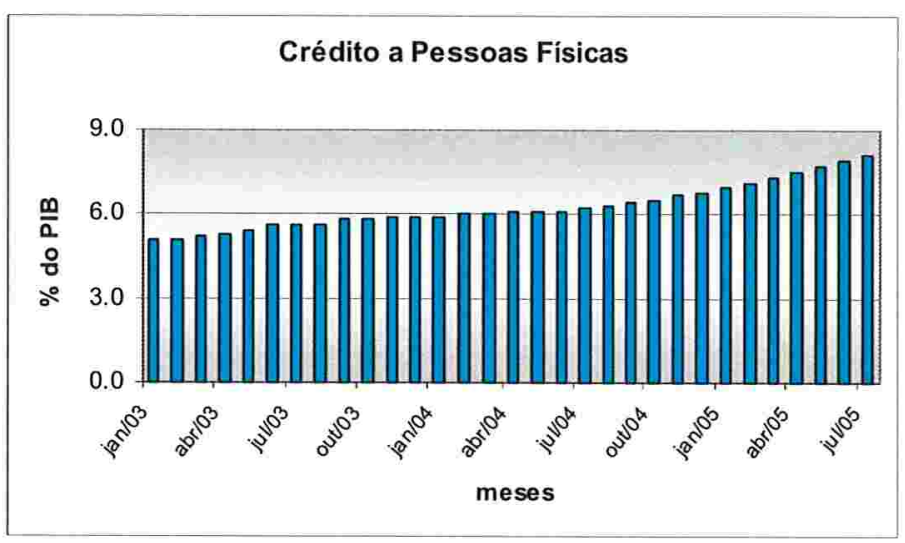

Figura 1.1: Evolução do crédito para pessoas físicas. Fonte: Banco Central do Brasil.

As condições sócio-econômicas promissoras descritas anteriormente, somadas ao elevado índice de trabalho informal no país ${ }^{5}$ e ao cenário de alta competitividade no mercado, faz com que vislumbremos a oportunidade de criar métodos inteligentes para atrair e rentabilizar nichos específicos de clientes como o especificado anteriormente.

O objetivo desse trabalho é propor um mecanismo de inferência de renda para esses clientes, desde que já possuam um relacionamento com a instituição proponente e, assim propor políticas de manutenção de linha de crédito concedida e/ou até pré-aprovar outras linhas de crédito mais convenientes para ambas as partes.

\footnotetext{
${ }^{5}$ Informalidade atinge 38,1 milhões no país. Folha de S. Paulo, 8 fev. 2004.
} 


\subsection{Modelos aplicados à decisões de crédito}

Desde primórdios do sistema financeiro bancário até o início do século $\mathrm{XX}$, a análise de crédito se dava através de analistas que, de acordo com uma análise criteriosa do perfil de cada proponente a crédito, decidia a concessão ou não e o valor do empréstimo que poderia ceder de modo que o cliente conseguisse honrar com suas dividas futuramente (Thomas et al., 2002). Depois de iniciado o relacionamento do cliente com a instituição, esse só era contatado se não cumprisse o acordo firmado, numa ação já caracterizada de cobrança. Com o aumento expressivo do número de propostas e da variedade de produtos de crédito, a análise individual tornou-se inviável. Teria um impacto enorme tanto no custo estrutural e de pessoal, quanto no tempo de resposta. Outro fator a ser levado em conta é que, pelo fato da análise ser feita por uma mão de obra humana, esse mecanismo de análise seria repleto de subjetividade e estaria sujeito a diferentes critérios, ou seja, uma mesma proposta poderia ser considerada negada por um analista e aprovada por outro ou, então, um mesmo analista poderia aprovar uma proposta hoje e negá-la amanhã gerando inconsistências na análise.

Com o intuito de solucionar os problemas descritos acima, diversos modelos estatísticos vêm sendo propostos e utilizados em diversos momentos do ciclo de crédito.

Para a concessão de crédito a clientes novos existem os chamados modelos de credit scoring (Hand \& Henley, 1997; Thomas, 2002). O objetivo dessa familia de modelos é estimar a probabilidade de um cliente vir a ser inadimplente num período de tempo pré-definido (geralmente um ano) baseado basicamente em suas informações cadastrais. Esses modelos embasam as decisões de concessão de crédito a clientes novos e podem ser usados também na definição do limite de crédito e na previsão de perda futura. 
Concedido o crédito, também é interessante um acompanhamento da trajetória financeira do tomador na instituição credora. Os modelos desenvolvidos com esse objetivo são chamados de modelos de behavioural scoring (Hoper \& Lewis, 1992). Esses são desenvolvidos de forma a estimar a probabilidade do cliente vir a ter problemas de crédito no produto já possuído nos próximos $n$ meses, com base em informações do seu comportamento na instituição credora. Com base nisso, a instituição pode tomar ações preventivas em relação ao cliente que passou a ter uma probabilidade alta de sinistro, antes que este ocorra.

Mesmo com toda uma monitoração implementada, a ocorrência de alguns sinistros é inevitável. Assim, os clientes inadimplentes passam a sofrer ações de cobrança. Vários são os métodos utilizados pelas instituições financeiras para pressionar o cliente a quitar suas dividas. Dentre outras podemos citar: telefonemas, cartas de advertências, renegociações, e, por fim, a negativação do cliente em órgãos de proteção ao crédito. Métodos de cobrança inapropriados geralmente causam certo atrito com o cliente, que pode deixar de ser um potencial futuro cliente novamente. Assim, surgem então os modelos de collection scoring, que visam estimar a probabilidade do cliente inadimplente vir a quitar suas dívidas daqui a $n$ meses. Com isso a instituição determina o método, a intensidade e a longevidade da cobrança de acordo com o perfil do cliente.

Visando uma expansão da carteira de clientes, é interessante que as instituições descubram alguns segmentos de clientes em potencial para oferecer seus produtos, otimizando assim a relação receita/custos das campanhas de marketing. Os modelos de propensity scoring (Tsai \& Yeh, 1999) podem ajudar a identificar quem são e quantos desses segmentos existem e até indicar o canal de venda mais apropriado (mala direta, telemarketing, etc.) para o contato, direcionando os esforços para clientes com maior propensão a obter determinados produtos. É interessante frisar nesses casos que é fundamental a interação desses modelos com os modelos de risco de concessão de crédito (credit e behavioraul scoring), pois geralmente um 
cliente mais propenso a adquirir produtos de crédito e é aquele com risco mais alto. Assim, seria interessante ofertar o produto não para todos os clientes com alta propensão, mas também para aqueles que possuam um risco baixo de inadimplência.

Além dos modelos já discutidos, existem modelos desenvolvidos com a finalidade de prever a probabilidade de cancelamento de um produto (attrition scoring), a probabilidade de o cliente vir a dar lucro à instituição (profit scoring, Oliver, 1993) e até mesmo a probabilidade de fraude (fraud scoring, Henley, 1995) haja visto que clientes mal intencionados desde o principio possuem uma pontuação alta no credit scoring, implicando assim num falso baixo risco de inadimplência.

Uma característica intrínseca ao cliente e de suma importância em todos os módulos de crédito e modelos citados acima é a renda mensal, muitas vezes de difícil mensuração. A renda é sem dúvida uma quantificação do poder de compra do cliente e, assim, muito associada aos fatores citados anteriormente, dentre eles: o risco de inadimplência, a propensão à compra de um determinado produto ou pacotes de produtos, tempo de quitação de suas dividas, chegando até ao potencial de rentabilidade que esse cliente pode gerar à instituição. Sendo assim, as instituições costumam quantificar todos seus limites de crédito concedidos em função da renda do cliente, de modo que é necessário que essa informação seja confiável. Devido a esse fato, muitas instituições assumem uma postura conservadora em relação a essa informação, considerando apenas a renda que o cliente consiga de fato comprovar. Esse cenário conservador ocasiona efeitos insatisfatórios para ambos os lados: pode acender no cliente um descontentamento em relação aos serviços prestados que pode até levá-lo ao cancelamento do relacionamento com a instituição e, por outro lado, pode levar a uma perda de receita à instituição que concede menos crédito do que o cliente supostamente consegue pagar.

É importante também que as instituições sejam pró-ativas e ofertem produtos de crédito que não comprometam a capacidade de pagamento 
mensal do cliente até mesmo antes do cliente solicitá-las. Desta forma, a desatualização dos dados também pode ocasionar ineficiência nesse processo de pré-aprovação.

Assim, é de suma importância um mecanismo que embase as decisões relativas à renda real para crédito do cliente e que essa possa ser revista periodicamente com o objetivo tanto de atender às necessidades reais dos clientes quanto à rentabilização máxima da carteira.

\subsection{Objetivos e estrutura}

Apesar do conhecimento do valor da renda ser essencial para todos os tipos de clientes, destacamos nesse trabalho em especial os clientes que tem uma grande parte de sua renda mensal composta por uma fonte variável, de difícil comprovação. Podemos citar como exemplo de clientes com as características descritas os médicos, advogados, dentistas, comerciantes, arquitetos, engenheiros e consultores em geral. Esses profissionais geralmente possuem carteira assinada, porém parte de seus rendimentos provém da informalidade. Possuem uma volatilidade em sua renda que por diversas vezes é sazonal e não são raras as vezes que trabalham em mais de uma empresa e/ou ainda como autônomos.

O objetivo dessa dissertação é criar um modelo estatístico para previsão de renda de clientes de um banco de grande porte com o intuito de viabilizar a manutenção de suas linhas de crédito e assim minimizar o tanto o efeito do conservadorismo no momento da contratação, como o efeito de eventuais desatualizações em seu cadastro, fidelizando e rentabilizando o cliente cada vez mais.

Como não há um histórico da renda efetiva para a maioria dos clientes no segmento estudado, foram adaptadas para esse contexto metodologias pertencentes à família de modelos chamada de análise de sobrevivência. 
Análise de sobrevivência é um conjunto de técnicas estatísticas desenvolvidas originalmente na área médica, com o intuito de detectar diferenças no tempo de sobrevida de pacientes que são submetidos a algum tratamento, cuja eficiência deve ser testada. Nesse tipo de experimento é comum que não se conheça o tempo de vida exato de alguns pacientes devido a diversos motivos, como por exemplo: abandono do estudo, término do periodo de acompanhamento, morte por outras causas que não as de interesse, etc. Apesar de não se conhecer o tempo de vida com exatidão para esses pacientes com informações incompletas (usualmente chamadas de informações censuradas), geralmente temos pelo menos a informação a respeito do tempo de vida minimo e/ou máximo de sobrevivência. Para a incorporação dessas informações censuradas na análise, tornou-se necessário o desenvolvimento dessa metodologia especial.

Devido a sua grande aplicabilidade, essa metodologia se popularizou a partir dos 80 e vem sido estendida desde então para diversas áreas do conhecimento como, por exemplo, controle de qualidade (Wasserman, 2003), marketing (Franses \& Paap, 2001), finanças (Wooldridge, 2002) e até mesmo na análise de crédito (Stepanova \& Thomas, 2000).

Essa dissertação contribui para uma nova aplicação dessa técnica com uma grande diferença na estruturação conceitual. Aqui, é considerado como variável resposta a renda do cliente e não mais o tempo até a ocorrência de um evento determinado, como nos exemplos anteriores.

No Capitulo 2 são feitas considerações a respeito do problema e dos dados a serem analisados.

No Capítulo 3, um breve resumo da teoria de análise de sobrevivência é apresentado e a adaptação conceitual para o problema analisado é discutido.

No Capítulo 4, a técnica é aplicada a dados reais de uma grande instituição financeira e, por fim, no Capitulo 5 temos conclusões, considerações finais e sugestões para estudos futuros. 


\section{Descrição do estudo}

Uma instituição bancária deseja conhecer a renda efetiva de seus clientes pertencentes a um segmento especifico da população de profissionais liberais cuja comprovação de renda é limitada, para que possa manter um relacionamento mais adequado, gerando satisfação tanto para a própria instituição credora, como para o tomador de crédito.

Nesse capitulo será discutida a natureza do problema e como a abordagem das técnicas de análise de sobrevivência pode ajudar a resolvê-lo. Na Seção 2.1 será exposto o problema a ser resolvido e na Seção 2.2 será feita uma breve descrição dos dados amostrados para análise que posteriormente será apresentada no Capítulo 4.

\subsection{Caracterização do problema}

O grande desafio é construir a base de dados para a modelagem, dado que não é possivel obter informação acertiva a respeito da variável resposta. Especificamente, não conhecemos a renda efetiva de uma grande parcela dos clientes nesse segmento. Entretanto, para a maioria desses clientes, dispomos de duas informações que nos ajudam a delinear a variável resposta: a renda comprovada e a renda declarada.

A renda comprovada é a fração da renda do cliente que pode ser comprovada por algum documento confiável para o banco como um holerite ou declaração do imposto de renda. Essa tem sido a renda até então assumida pela instituição como renda efetiva para fins de limite de crédito e que se 
acredita ser subestimada para esse público especifico em alguns casos. A renda declarada é a renda que o cliente afirma receber mensalmente, porém de comprovação duvidosa como, por exemplo, contratos de aluguéis, comércio próprio, aplicações financeiras, etc.

Acreditando que a renda do cliente é pelo menos o que ele consegue comprovar e no máximo o que ele diz ganhar, iremos supor que o cliente recebe pelo menos a renda comprovada e no máximo a renda declarada. Essa informação será tratada como uma resposta censurada por intervalo. Caso a renda declarada seja igual à renda comprovada, consideramos uma informação não censurada (o que no contexto de análise de sobrevivência é conhecido como falha), ou seja, para esses clientes conhecemos a renda efetiva real.

Alguns clientes na amostra possuem informação para apenas uma das rendas mencionadas acima. Por exemplo, clientes cuja profissão é exclusivamente informal só possuem informação da renda declarada, pois todos os meios de comprovação disponiveis são considerados "nãoconfiáveis". Por outro lado, para clientes que simplesmente não preenchem o cadastro ou para clientes que possuem um serviço registrado em carteira, porém alegam ter uma variação grande na renda mensal devido a serviços esporádicos, é disposta apenas a informação de renda comprovada, pois não existe nenhum tipo de comprovação dessa variabilidade mensal na renda. Para efeito de modelagem, os clientes sem informação de renda comprovada serão tratados como censurados à esquerda de modo que é suposto que o cliente ganha no máximo a renda declarada. Similarmente, clientes com informação apenas da renda comprovada serão considerados como censurados à direita. A Figura 2.1 ilustra o conceito discutido acima.

É importante destacar que o fato do cliente ter uma renda declarada diferente da renda comprovada (censuras à esquerda e intervalar) tanto pode ser devido ao fato do cliente realmente possuir uma fonte extra na composição de sua renda mensal como pode ser que o cliente esteja precisando de crédito 
e assim tentando conseguir um empréstimo maior do que aquele que consegue pagar.

Outro ponto interessante a ser frisado é que, devido à política interna da instituição credora, apenas clientes com renda acima de um certo valor (no caso, $\mathrm{R} \$ 300,00 /$ mês) podem obter empréstimo financeiro. Assim, podemos afirmar que na coleta da amostra não existirão clientes com a renda mensal abaixo de $R \$ 300,00$. Isso caracteriza outra informação relevante no delineamento da variável resposta que no contexto de análise de sobrevivência é conhecido como truncagem à esquerda.

A incorporação dessas informações truncadas e censuradas deve ser considerada na estimação dos parâmetros do modelo e serão adaptadas técnicas de análise de sobrevivência que serão discutidas no Capítulo 3.

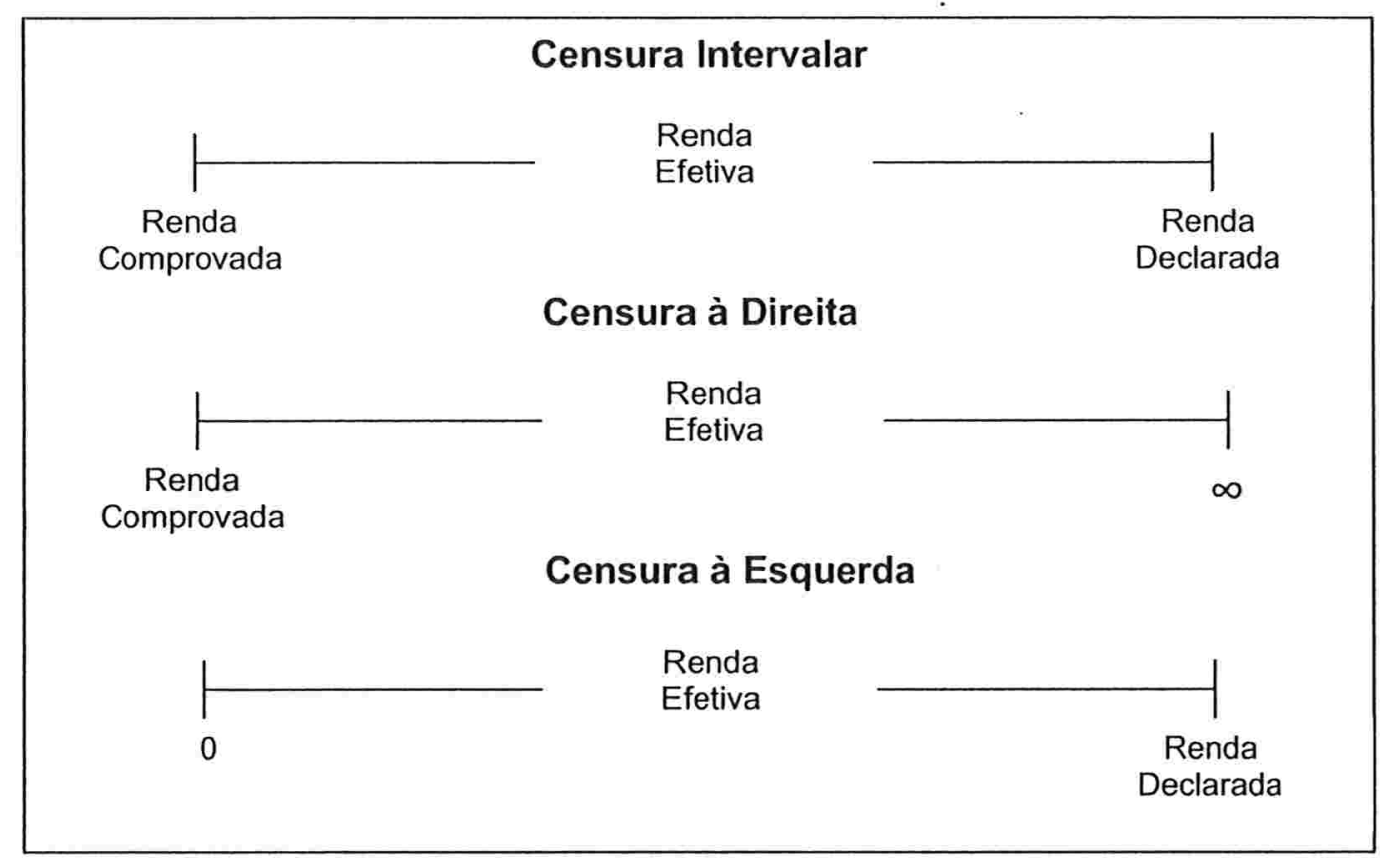

Figura 2.1: Desenvolvimento da variável resposta utilizada

Para desenvolvimento dos modelos, foi coletada uma amostra de 3020 clientes nesse segmento de interesse, onde foram observadas diversas variáveis tanto cadastrais quanto comportamentais para estudar sua influência na distribuição da renda mensal efetiva. 


\subsection{Descrição dos dados}

Os dados analisados nesse estudo são obtidos de clientes de uma grande instituição financeira, pertencentes ao segmento de profissionais liberais, com alguma forma de empréstimo adquirida no período de maio a julho de 2004.

As variáveis coletadas podem ser divididas em dois grupos: variáveis cadastrais e variáveis comportamentais.

As variáveis cadastrais são informações referentes às características intrínsecas do cliente como, por exemplo: idade, sexo, estado civil, CEP, profissão, etc. Essas informações geralmente são de natureza sóciodemográfica e tendem, em sua maioria, a ser constantes em relação ao tempo.

Já as variáveis ditas comportamentais têm o intuito de mensurar o relacionamento dos clientes com a instituição credora como, por exemplo, tempo de conta corrente, produtos adquiridos, lançamentos de crédito e de débito, etc. Esse grupo de variáveis é mais instável em relação ao tempo, de modo que, para algumas delas, foram coletados os históricos de cinco meses de forma a possibilitar uma análise mais abrangente e consistente. $O$ tratamento dado para consolidação longitudinal dessas variáveis será discutido no Capítulo 4.

Como o estudo tem por objetivo a obtenção de uma visão consolidada por cliente, algumas variáveis comportamentais precisam ser consolidadas para clientes com mais de uma conta corrente e/ou mais de um produto contratado na instituição. A Tabela A.1 mostra as variáveis coletadas, suas respectivas descrições e, quando necessário, as consolidações realizadas.

Além das variáveis citadas, temos variáveis que constituirão a resposta do modelo: a renda declarada e a renda comprovada. Para a maioria dos clientes possuímos as duas rendas preenchidas, sendo que para $40 \%$ dos clientes amostrados elas são valores diferentes entre si, o que caracteriza a censura intervalar, e para $23 \%$ elas coincidem, o que chamamos aqui de falhas. $32 \%$ 
dos clientes amostrados não possuem informação de renda declarada (censura à direita), o que caracteriza um público com um perfil de renda flutuante. A distribuição dos tipos de respostas é apresentada na Figura 2.2.

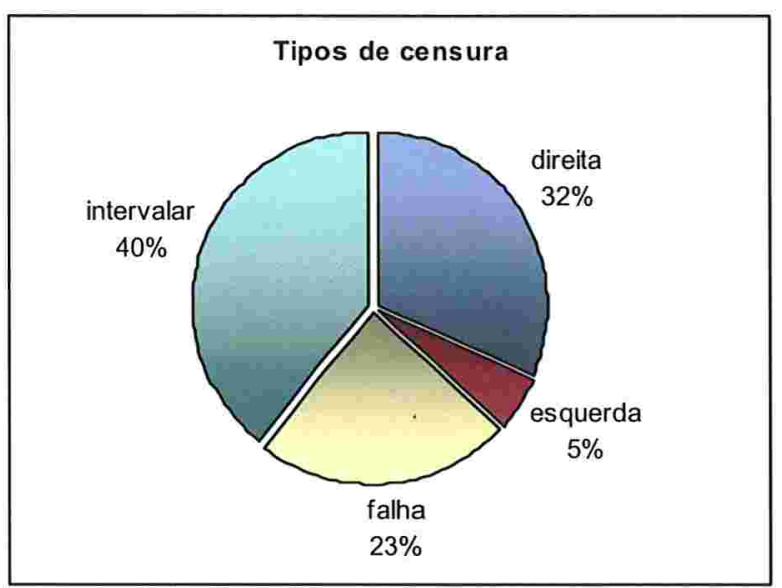

Figura 2.2: Distribuição do tipo de censura na amostra 


\section{Metodologia}

Nesse capitulo serão discutidos os conceitos inerentes às técnicas de análise de sobrevivência e também uma apresentação metodológica dos modelos já existentes e que serão utilizados ao banco de dados descrito no capítulo anterior.

\subsection{Conceitos iniciais}

Para possibilitar a discussão que segue, definimos alguns conceitos que serão usados posteriormente no desenvolvimento metodológico dos modelos.

Seja $X$ uma variável aleatória contínua não negativa, com função densidade de probabilidade $f(u ; \boldsymbol{\theta})$, indexada por um vetor de parâmetros $p$-dimensional $\boldsymbol{\theta}$. A função distribuição de probabilidade acumulada é definida como:

$$
F(x ; \theta)=\int_{-\infty}^{x} f(u ; \theta) d u, \quad x \geq 0
$$

e a função de sobrevivência é dada por:

$$
S(x ; \boldsymbol{\theta})=1-F(x ; \boldsymbol{\theta})=\int_{x}^{\infty} f(u ; \boldsymbol{\theta}) d u, \quad x \geq 0 .
$$


Outras expressões comumente utilizadas em análise de sobrevivência são as das funções de risco e risco acumulado. A função de risco pode ser interpretada como o risco de um indivíduo com idade $x$ experimentar o evento no próximo instante, e pode ser definida como:

$$
h(x ; \theta)=\lim _{\Delta x \rightarrow 0} \frac{P\{x \leq X<x+\Delta x \mid X \geq x\}}{\Delta x}=\frac{f(x ; \theta)}{S(x ; \theta)}=\frac{-d \ln [S(x ; \theta)]}{d x}, x \geq 0
$$

Por sua vez, a função de risco acumulado é dada por:

$$
H(x ; \theta)=\int_{0}^{x} h(u ; \theta) d u=-\ln [S(x ; \theta)], \quad x \geq 0
$$

Dada uma amostra $\boldsymbol{x}=\left(x_{1}, x_{2}, \ldots, x_{n}\right)$ da variável aleatória $X$ com função densidade de probabilidade $f_{x}(x ; \boldsymbol{\theta})$, temos que, sob a suposição de independência de $x_{i}, i=1, \ldots, n$, a função de verossimilhança pode ser escrita como:

$$
L(\boldsymbol{\theta} / \boldsymbol{x})=f_{x}(\boldsymbol{x} ; \boldsymbol{\theta})=\prod_{i=1}^{n} f\left(x_{i} ; \boldsymbol{\theta}\right)
$$

Procedimentos baseados na verossimilhança visam achar o valor de $\theta$ que maximiza a probabilidade de selecionar a amostra coletada.

Como já comentado, a motivação principal do desenvolvimento de modelos de análise de sobrevivência é a incorporação de informações incompletas na análise, para uma melhor inferência a respeito dos parâmetros de interesse. Assim, primeiramente, faz-se necessária a compreensão do que vem a ser censura e truncagem, suas diferenças, e como são utilizadas na estimação dos parâmetros. 


\subsection{Censura e Truncagem}

Em experimentos cujo objetivo é estudar o tempo até a observação de um determinado evento de interesse (usualmente chamado de morte ou falha), é comum que não seja possivel observar o tempo exato de sua ocorrência, para algumas das unidades amostrais. Essa característica peculiar é conhecida como informação censurada e pode ocorrer de diversas formas de acordo com o tipo de experimento. Existem basicamente três tipos de censuras: à direita, à esquerda e intervalar. Cada tipo de censura tem uma contribuição diferenciada na função de verossimilhança, que é a principal fonte de informação para as inferências dos parâmetros e será melhor explorada nas seções subseqüentes.

Uma segunda característica presente em alguns estudos desse tipo é conhecida como truncagem. Truncagem à esquerda ocorre quando as unidades amostrais entram no estudo somente se possuírem um tempo de vida maior que um determinado valor estipulado previamente e, sendo assim, serão acompanhadas desde esse valor estipulado até a ocorrência do evento ou da censura. Truncagem à direita ocorre quando apenas individuos que já experimentaram o evento de interesse são observados. O impacto nas análises, quando os dados apresentam truncagem, se dá através do uso de uma distribuição condicional na construção da função de verossimilhança.

A principal diferença entre censura e truncagem é que indivíduos que sofreram truncagem não estão presentes na amostra enquanto que indivíduos censurados sim, apesar de apresentarem informação da variável reposta incompleta.

Duas suposições primordiais para a construção da função de verossimilhança em modelos de sobrevivência e que são assumidas no decorrer das demonstrações que se seguem são que as variáveis aleatórias 
representando censura são independentes das variáveis aleatórias representando os tempos de vida e que as variáveis explicativas a serem usadas não são correlacionadas com quaisquer parâmetros que a distribuição das censuras possa depender. Caso essas suposições não sejam válidas, devem ser utilizadas técnicas especiais para censuras informativas (Siannis, 2004) que não serão discutidas neste trabalho. Maiores detalhes sobre essas suposições no problema estudado serão considerados na Seção 3.5

A seguir será apresentada uma visão mais aprofundada de cada tipo de censura e como são feitas suas respectivas contribuições na função de verossimilhança.

\section{Censura à direita}

Dizemos que a observação sofreu uma censura à direita quando não conhecemos seu tempo de vida exato, porém sabemos que é maior que um determinado valor. Esse tipo de censura é comum de ser observada em estudos clínicos, em que o interesse principal é examinar a eficácia de uma droga no tempo de vida (ou cura) de pacientes com uma determinada doença. Nesse exemplo, o evento de interesse é a morte do paciente causada pela doença estudada. Porém, devido ao tempo necessário e ao custo associado, o experimento costuma acabar antes que todos os pacientes da amostra apresentem o evento de interesse. Para os pacientes que morreram devido à doença antes do término do estudo, o tempo exato de sobrevivência é conhecido. Para os pacientes ainda vivos no término do acompanhamento, não é conhecido o seu tempo de sobrevivência exato, porém sabe-se que ele é maior que o momento do fim do estudo. Esses pacientes são classificados como censurados à direita, mais especificamente, sofrem censura tipo I.

Outros pacientes que eventualmente podem ser classificados como censurados no exemplo acima são pacientes que abandonaram o estudo antes do término ou que morrem durante o estudo devido a alguma causa 
independente da doença estudada, como por exemplo, um acidente de carro. Nesse caso, temos censura do tipo aleatório.

Para fins de demonstrações teóricas, adotaremos a seguinte notação. Seja $X_{i}$ e $R_{i}$ variáveis aleatórias relativas ao tempo de vida e ao tempo de censura do $i$-ésimo indivíduo da amostra, respectivamente. Assuma que as variáveis aleatórias representando os tempos de vida $(X)$ entre os indivíduos são independentes e tem função de densidade $f(x)$ e função de sobrevivência $S(x)$. Assim, observamos na prática, para o $i$-ésimo indivíduo o par de variáveis aleatórias $\left(T_{i}, \delta_{i}\right)$, sendo $T_{i}=\min \left(X_{i}, R_{i}\right)$ e $\delta_{i}=\mathrm{I}_{\left(\mathrm{X}_{\mathrm{i} S \mathrm{R}}\right)}$, em que $\delta_{i}=1$ se para $\mathrm{o}$ indivíduo $i$ é observado o evento de interesse e $\delta_{i}=0$, caso contrário. Os indivíduos censurados à direita contribuem para a verossimilhança com sua função de sobrevivência, calculada no tempo de censura observado $t_{i}$ de modo que toda a informação que temos é que o tempo de vida é maior ou igual ao instante de censura observado. Já para os indivíduos que apresentaram o evento, a informação diz respeito à probabilidade do evento ocorrer em $t_{i}$, e é representada, no caso contínuo, por $f\left(t_{i}\right)$. A função de verossimilhança da amostra $\left(t_{i}, \delta_{i}\right) i=1, \ldots, n$ (essa suposta independente e identicamente distribuida) é dada por:

$$
L=\prod_{i=1}^{n}\left[f\left(t_{i}\right)\right]^{\delta}\left[S\left(t_{i}\right)\right]^{1-\delta}
$$

Uma derivação mais formal de (3.6) pode ser encontrada em Lawless (2003) ou Klein \& Moeschberger (1997).

\section{Censura à esquerda}

Quando no início do experimento o evento de interesse já ocorreu e não é mais possivel conhecer $o$ instante exato, tem-se apenas a informação que o tempo até o evento è anterior ao início o estudo. Esse tipo de censura é conhecido como censura à esquerda e sua ocorrência é mais comum em 
estudos retrospectivos. Como exemplo, podemos citar um experimento que tem como objetivo estudar a idade em que adolescentes começam a fumar. É colhida então uma amostra de fumantes e é perguntado com qual idade o entrevistado fumou seu primeiro cigarro. Uma resposta possivel a essa pergunta seria: "Comecei a fumar bem cedo, mas não me lembro exatamente quando". Assim, esse seria um indivíduo censurado à esquerda, pois é sabido que o evento de interesse já aconteceu, mas não se sabe quando exatamente.

Similarmente à seção anterior, seja $X_{i}$ e $L_{i}$ variáveis aleatórias relativas ao tempo de vida e ao tempo de censura do $i$-ésimo indivíduo da amostra e $f(t)$ e $F(t)$ as funções densidade e distribuição do tempo de vida respectivamente. Assumindo independência da amostra obtida, observamos o par $\left(T_{i}, \delta_{i}\right)$, sendo agora $T_{i}=\operatorname{máx}\left(X_{i}, L_{i}\right)$ e $\delta_{i}=I\left(X_{i}>\operatorname{Li}\right)$. Assim a função de verossimilhança para a amostra pode ser escrita como:

$$
L=\prod_{i=1}^{n}\left[f\left(t_{i}\right)\right]^{\delta}\left[F\left(t_{i}\right)\right]^{1-\delta}
$$

Maiores detalhes podem ser encontrados em Lawless (2003) ou Klein \& Moeschberger (1997).

\section{Censura intervalar}

Em alguns tipos de experimentos é possivel observar fenômenos em que o tempo até o evento de interesse acontece dentro de um intervalo. Em estudos clínicos, por exemplo, onde o interesse é estudar o tempo de aparecimento de certa doença em pessoas saudáveis expostas a algum fator de risco, são necessários diagnósticos laboratoriais periódicos e, não raras vezes, a doença (evento) é constatada a partir de um determinado exame. Nesse caso, sabe-se que a doença ocorreu num intervalo de tempo entre dois exames realizados. Esse tipo de censura é chamada de censura intervalar e a função de verossimilhança nesse caso é dada por: 


$$
L=\prod_{i=1}^{n}\left[f\left(t_{i}\right)\right]^{\delta}\left[S\left(l_{i}\right)-S\left(r_{i}\right)\right]^{1-\delta} \quad \delta i=\left\{\begin{array}{l}
1, \text { se } l_{i}=r_{i}=t_{i} \\
0, \text { se } l_{i} \neq r_{i}
\end{array}\right.
$$

sendo $l_{i}$ e $r_{i}$ os valores observados para o $i$-ésimo individuo dos limites inferior e superior do intervalo de tempo censurado respectivamente. Se $l_{i}=r_{i}$, sabe-se o tempo exato da ocorrência do evento.

É interessante notar que esse tipo de censura pode ser visto como uma generalização das outras duas vistas anteriormente. Quando $l_{i}=0$, temos que $S\left(l_{i}\right)=1$ o que remete a expressão (3.8) à forma de (3.7) que é a verossimilhança para censura à esquerda. Da mesma forma quando temos ri = œ a expressão (3.8) toma a forma de (3.6) que é a expressão no caso de censura à direita.

Uma aplicação prática pode ser encontrada em De Gruttola \& Lagakos (1989). Quando os intervalos de censura não são aleatórios, abordagens mais simples não discutidas no presente trabalho podem ser aplicadas. Mais detalhes podem ser estudados em Collet (1994).

\section{Truncagem à esquerda}

Truncagem à esquerda acontece quando apenas individuos com tempo de sobrevivência maior que um instante determinado $Y$ (independente do tempo até a ocorrência do evento $X$ ) estão presentes na amostra. Deste modo, a ocorrência de um evento num tempo $X<Y$ não pode ser observada na amostra, em contraste com o que acontece na censura à esquerda, onde temos pelo menos alguma informação a respeito do tempo até o evento, mesmo que esse tenha acontecido anteriormente ao início do estudo.

Um exemplo de estudo com truncagem à esquerda pode ser visto em Hyde (1980). O objetivo do experimento foi estudar o tempo de vida de residentes de uma casa de repouso localizada na Califórnia. Foram coletadas amostras de moradores e anotada a idade em que o entrevistado entrou na instituição 
(evento de truncagem) e a quantidade de meses até o falecimento ou até que deixasse a instituição. Pelo fato do indivíduo precisar apresentar uma idade suficientemente avançada para ingressar na instituição, indivíduos que morreram antes de certa idade não fazem parte da amostra de estudo.

Devido ao fato de ser possivel observar apenas individuos com tempo de sobrevivência $X$ maior ou igual ao tempo de truncagem $Y$, é necessário o uso de uma distribuição condicional na montagem da função de verossimilhança, que pode ser escrita como:

$$
L=\prod_{i} \frac{f\left(X_{i}\right)}{S\left(Y_{i}\right)}
$$

Maiores detalhes a respeito desse modelo podem ser encontrados em Amemiya (1973) ou Klein \& Moeschberger (1997).

\section{Truncagem à direita}

$\mathrm{Na}$ truncagem à direita apenas indivíduos que experimentaram o evento podem fazer parte da amostra de estudo. Em estudos de mortalidade baseados em relatos de mortes pode acontecer esse tipo de censura como é o caso do experimento relatado por Lagakos e colaboradores (1988). Esse estudo considera o tempo até o desenvolvimento de AIDS em indivíduos contaminados por transfusão de sangue. Nesse método de coleta de amostra, apenas indivíduos que desenvolveram AIDS estão presentes no estudo. Indivíduos HIV positivos, porém que não desenvolveram a doença não foram coletados.

Como nesse tipo de experimento apenas eventos são observados, a função de verossimilhança tem a forma:

$$
L=\prod_{i} \frac{f\left(Y_{i}\right)}{1-S\left(Y_{i}\right)}
$$


em que $Y_{i}$ representa o tempo até o acontecimento do evento para o $i$-ésimo indivíduo.

Pela natureza dos dados apresentados estudo descrito na Seção 2.2 do Capítulo 2, é observada a presença dos três tipos de censura citados acima bem como também truncagem à esquerda. Deste modo a verossimilhança a ser maximizada considerando todas as características pode ser escrita como:

$$
L=\prod_{i \in D} \frac{f\left(t_{i}\right)}{S\left(Y_{i}\right)} \prod_{i \in R} \frac{S\left(t_{i}\right)}{S\left(Y_{i}\right)} \prod_{i \in L}\left[1-\frac{S\left(t_{i}\right)}{S\left(Y_{i}\right)}\right] \prod_{i \in l}\left[\frac{S\left(l_{i}\right)-S\left(r_{i}\right)}{S\left(Y_{i}\right)}\right]
$$

em que $D$ é o conjunto dos índices para os indivíduos em que o tempo exato de vida é observado, $R$ é o conjunto dos índices para os indivíduos com observações censuradas à direita, $L$ o conjunto dos índices para os indivíduos com observações censuradas à esquerda e I o conjunto dos índices para os indivíduos com observações com censura intervalar.

\subsection{Modelos de sobrevivência}

Nessa seção serão discutidos alguns modelos comumente utilizados em análise de sobrevivência e que foram aplicados para as análises dos dados desta dissertação. Serão apresentados métodos de estimação e algoritmos de ajuste utilizados.

Na Seção 3.3.1 é apresentada uma breve revisão, baseada na abordagem não-paramétrica, sendo a abordagem paramétrica considerada na Seção 3.3.2. O enfoque semi-paramétrico é discutido na Seção 3.3.3. 


\subsubsection{Modelos Não-Paramétricos}

Os modelos não-paramétricos visam estudar a distribuição do tempo de sobrevivência, sem pressupor uma distribuição paramétrica conhecida. A única suposição que será feita para construção desses modelos é que o mecanismo de falha é independente do mecanismo de censura. A abordagem apresentada nessa seção pressupõe populações homogenias, de forma que não permite a incorporação de covariáveis explicativas. Será utilizada no presente trabalho apenas na análise de resíduos, para verificação do ajuste dos modelos paramétricos e semi-paramétricos.

No caso de dados censurados à direita, o estimador mais utilizado é o estimador de Kaplan-Meier (Kaplan \& Meier, 1957). Turnbull (1976) sugere uma modificação do algoritmo citado baseado no algoritmo iterativo EM (Dempster et al., 1977) para a estimação não-paramétrica da função de sobrevivência no caso de censura intervalar. A macro ICE foi construída utilizando esse algoritmo, que será brevemente descrito a seguir.

Seja $0=s_{0}<s_{1}<\ldots<s_{m}$ um conjunto de pontos que englobam todos os extremos do intervalo da censura $L_{i}, R_{i}$, para $i=1, \ldots, n$. Para a $i$-ésima observação defina o peso $\alpha_{i j}=1$ se o intervalo $\left(s_{j-1}, s_{j}\right.$ ] está contido no intervalo $\left(L_{i}, R_{i}\right]$ e $\alpha_{i j}=0$, caso contrário. Um chute inicial aleatório para a função de sobrevivência $S$ é dado. O algoritmo então segue os seguintes passos:

1) Calcular a probabilidade que um evento ocorra no tempo $s_{j}, p_{j}=S\left(s_{j-1}\right)$ $S\left(s_{j}\right), j=1, \ldots, m$.

2) Estimar o número de eventos ocorridos em $s_{j}$ por $d_{j}=\sum_{i=1}^{n} \frac{\alpha_{i j} p_{j}}{\sum_{k} \alpha_{i k} p_{k}}$

3) Calcular o número estimado de unidades experimentais em risco no tempo $s_{j}$ por $Y_{j}=\sum_{k=j}^{m} d_{k}$

4) Calcular o estimador Kaplan-Meier usando os dados obtidos nos passos 2 e 3. Parar o processo iterativo se, para um $\varepsilon>0$ pequeno pré-fixado 


$$
\max _{t}\left|S^{(k)}(t)-S^{(k-1)}(t)\right|<\varepsilon
$$

em que $S^{(k)}(t)$ é a estimativa da função de sobrevivência no ponto $t$ no $k$-ésimo passo da iteração. Caso contrário, repetir os passos 1-3 usando a nova estimativa de $S$.

Mais detalhes sobre o algoritmo, assim como o cálculo dos desvios padrões das estimativas, podem ser encontrados em Turnbull (1976).

\subsubsection{Modelos Paramétricos}

Os modelos paramétricos pressupõem uma distribuição conhecida para o tempo de sobrevivência estudado, assim como uma relação entre o tempo de sobrevivência e as variáveis explicativas. De um modo geral, esses modelos relacionam a variável resposta com um efeito das covariáveis mais um termo de perturbação aleatório. Assim, o modelo assumido para a variável resposta $Y$ é dado por:

$$
Y=X \beta+\varepsilon
$$

em que $Y$ é o vetor da variável resposta (geralmente o logaritmo neperiano do tempo de falha $T$ ), $\boldsymbol{X}$ é a matriz das variáveis independentes, $\boldsymbol{\beta}$ o vetor de parâmetros desconhecidos, e $\varepsilon$ o termo de perturbação assumido vir de uma distribuição conhecida que pode depender de parâmetros de escala e locação desconhecidos.

Quando $Y$ é dado pelo logaritmo neperiano do tempo de falha, o modelo descrito acima é equivalente ao modelo de tempo de vida acelerado (Kalbfleisch \& Prentice, 1980), que assume um efeito das covariáveis multiplicativo nos tempos de falha. Esse efeito das covariáveis modifica a escala e não a localização da distribuição dos tempos. Seja então $T_{0}=\exp (\varepsilon)$ o valor amostrado da distribuição conhecida como basal, correspondente a 
uma unidade experimental com valores zero para as covariáveis e $T=\exp (Y)$. Então a expressão (3.12) pode ser reescrita como:

$$
T=\exp (X \boldsymbol{\beta}) T_{0}
$$

Consequentemente as funções de sobrevivência de $T$ e $T_{0}$ estão relacionadas através da expressão:

$$
S(t / X)=S_{0}(t \exp (-X \boldsymbol{\beta}))
$$

em que $S_{0}$ é a função de sobrevivência basal.

Usualmente, o modelo para a unidade experimental basal também contém um parâmetro de escala $\sigma$ que precisa ser estimado. Neste caso, o modelo paramétrico a ser ajustado é dado por:

$$
\boldsymbol{Y}=X \boldsymbol{\beta}+\sigma \varepsilon \quad \text { ou } \boldsymbol{T}=\exp (X \boldsymbol{\beta}) \boldsymbol{T}_{\mathrm{o}}^{\circ} .
$$

As distribuições mais utilizadas para o tempo de falha e as respectivas distribuições dos erros aleatórios, seguidas de suas funções de sobrevivência, estão resumidas na Tabela 3.1.

A estimação dos parâmetros $\beta$ e dos parâmetros relativos à distribuição assumida para os erros é feita através do método de máxima verossimilhança. Em geral, as distribuições não possuem uma expressão fechada para as derivadas da verossimilhança e é utilizado o método iterativo de NewtonRhapson para estimação dos parâmetros. Para as estimativas dos erros padrões será usada a matriz de informação observada, dada por:

$$
I_{o}(\theta)=-\frac{\partial^{2} /(y / \theta)}{\partial \theta^{2}}
$$


em que $I(y / \theta)$ é o logaritmo natural da função de verossimilhança e $\theta$ o vetor de parâmetros a ser estimado.

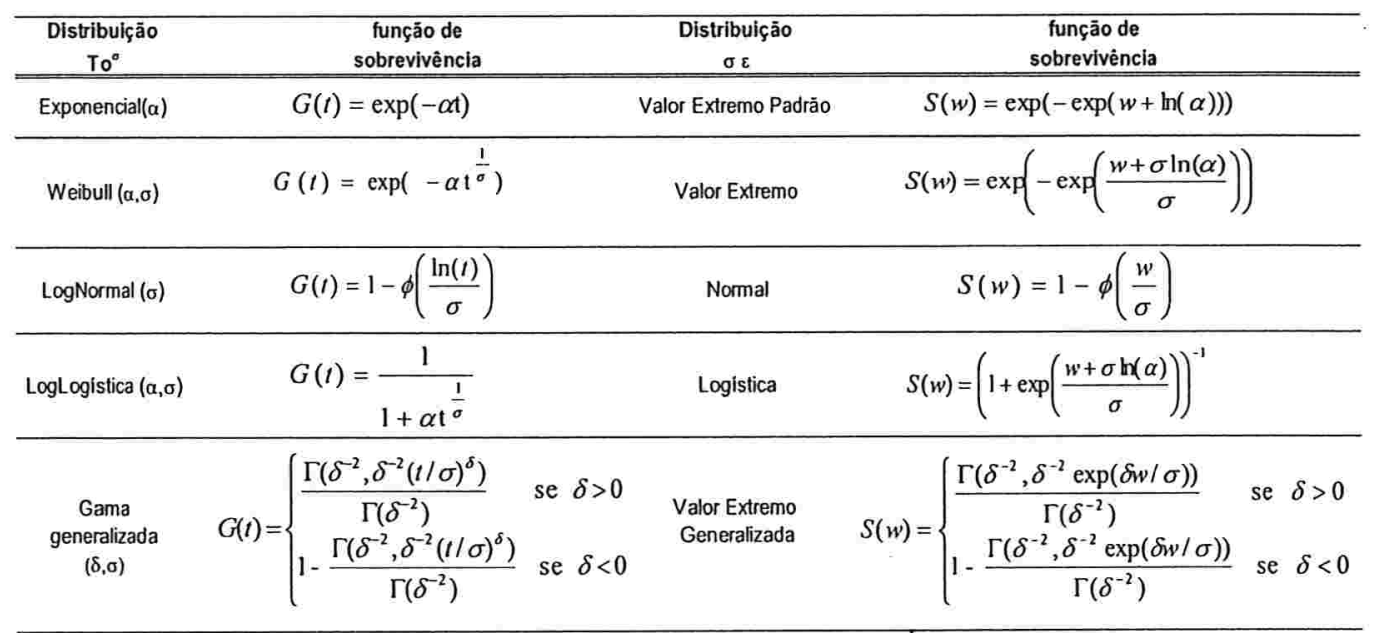

Tabela 3.1: Funções de sobrevivência mais utilizadas em modelos paramétricos.

$\Gamma(a)$ : função gama

$\Gamma(\mathbf{a}, \mathbf{b})$ : função gama incompleta

$\Phi($ a):função distribuição da normal padrão

Para um dado vetor de covariáveis $X$, a estimativa de máxima verossimilhança da função de sobrevivência no ponto $t$ se dá através da fórmula (3.13), substituindo os valores dos parâmetros desconhecidos pelas suas respectivas estimativas de máxima verossimilhança. Desta forma, é fácil desenvolver a expressão do quantil de ordem $p$ da distribuição da variável resposta, $y_{p}$. De (3.13) temos que:

$$
S\left(y_{p} / X\right)=S_{o}\left(y_{p} \exp (-X \boldsymbol{\beta})\right)=p
$$

Assim, conhecida a função de sobrevivência $S_{0}(t)$ temos que:

$$
y_{p} \cdot \exp (-\boldsymbol{X} \boldsymbol{\beta})=w_{p}
$$

em que $w_{p}$ é o quantil de ordem $p$ da função de sobrevivência basal. Assim chegamos que $\bar{y}_{p}$ é dado por: 


$$
\bar{y}_{p}=\exp (\boldsymbol{X} \widehat{\boldsymbol{\beta}})^{*} \widehat{W}_{p}
$$

em que $\widehat{\boldsymbol{\beta}}$ é o vetor de estimativas e $\overline{\boldsymbol{w}}_{p}$ é o $p$-ésimo quantil da distribuição basal já substituindo quaisquer parâmetros de forma ou de escala por suas respectivas estimativas de máxima verossimilhança. Os erros padrões das estimativas dos quantis são calculados através da matriz de variância e covariância dos parâmetros e uma expansão das estimativas dos quantis em série de Taylor pelo método delta resultando na fórmula abaixo:

$$
S T D=\sqrt{z^{\top} V z}
$$

com $V$ sendo a matriz de variância e covariância das estimativas dos parâmetros e $\mathbf{z}$ dado por:

$$
\boldsymbol{z}=\frac{\partial S(t / \boldsymbol{X})}{\partial \boldsymbol{\theta}}
$$

sendo $\boldsymbol{\theta}$ o vetor de parâmetros do modelo incluindo parâmetros de escala e de forma, eventualmente presente para a distribuição basal.

A maioria dos pacotes estatísticos já possui rotinas para ajuste dos modelos listados na Tabela 3.1 para vários tipos de censura, porém não permitem o uso de truncagem nas estimações simultaneamente. A macro no Apêndice $B$ foi construída com o intuito de suprir essa lacuna e será usada para o ajuste baseado nos dados, a serem discutidos no Capítulo 4 .

\subsubsection{Modelos Semi-Paramétricos}

A principal classe de modelos semi-paramétricos é a dos modelos de Cox (Cox,1972), que assume uma estrutura paramétrica para os efeitos das variáveis explicativas porém não supõe uma forma específica para a função de 
sobrevivência basal. A estrutura da função de risco para um individuo com variáveis explicativas $X$ no tempo $t$ é dada por:

$$
h(t / X)=h_{0}(t) \exp \left(X_{(t)} \boldsymbol{\beta}\right)
$$

em que $h_{o}(t)$ é uma função de risco basal, uma função não-negativa, porém arbitrária. Quando as covariáveis não dependem do tempo, (3.18) refere-se ao modelo de riscos proporcionais de Cox. É fácil ver que, sob o modelo (3.18) e a suposição de riscos proporcionais, a função de sobrevivência é modelada por:

$$
S(t / X)=S_{o}(t)^{\exp (x \beta)}
$$

Para a construção da função de verossimilhança nesse caso vamos representar os dados como a tripla $\left(L_{i}, R_{i}, X_{i}\right), i=1,2, \ldots, N$, com $L_{i}$ e $R_{i}$ representando os extremos do intervalo em que o evento para a $i$-ésima unidade amostral ocorreu e $X_{i}$ o respectivo vetor de covariáveis, independentes do tempo. Assumindo:

(i) que a distribuição do mecanismo de censura é independente tanto do tempo de falha como das covariáveis, e

(ii) cada indivíduo irá falhar a não ser que seja censurado, podemos escrever a função de verossimilhança (a menos de uma constante) como (Finkelstein, 1986):

$$
L=\prod_{i=1}^{N}\left[S\left(L_{i} / X_{i}\right)-S\left(R_{i} / X_{i}\right)\right]
$$

Como esse modelo não supõe uma estrutura paramétrica para a função de sobrevivência basal, a mesma precisa ser estimada por métodos não paramétricos. Em vista disso, defini-se $0=s_{0}<s_{1}<\ldots<s_{m}=\infty$ como tempos de acompanhamento distintos, obtidos através de $L_{i}$ e $R_{i}$. Então a função de verossimilhança em (3.20) será maximizada em relação a uma distribuição 
discreta com massa apenas no subconjunto de tempos $\left\{s_{0}, s_{1}, \ldots, s_{m}\right.$. Em particular, a $i$-ésima observação contribuirá para a verossimilhança apenas nos pontos em que foi observada, e pode ser representada por:

$$
\sum_{j=1}^{m} \alpha_{\bar{T}}\left[S\left(s_{i-1} / X_{1}\right)-S\left(s_{l} / X_{1}\right)\right]
$$

com $\alpha_{i j}=1$ se $\left(s_{j-1}, s_{j}\right]$ é um subconjunto de $\left(L_{i}, R_{i}\right]$, e 0 caso contrário.

Note que a expressão acima pode ser reescrita em termos da função de risco acumulada. Essa reparametrização apresenta duas vantagens: (1) concavidade da função de verossimilhança é garantida (Huang \& Wellner, 1997) e (2) a restrição $0 \leq S(t / X) \leq 1$, se resume a apenas $H(t / X) \geq 0$, ou seja, a funçãa de risco acumulada não tem limitante superior, o que facilita o processo iterativo. Desenvolvendo, o logaritmo da função de verossimilhança pode ser expresso por:

$$
\begin{aligned}
& I\left(\boldsymbol{\beta}, S_{1} \ldots S_{m-1} / \boldsymbol{X}_{i}\right)=\sum_{i=1}^{N} \ln \left[S\left(L_{i} / \boldsymbol{X}_{i}\right)-S\left(R_{i} / \boldsymbol{X}_{i}\right)\right] \\
& I\left(\boldsymbol{\beta}, s_{1} \ldots s_{m-1} / \boldsymbol{X}_{i}\right)=\sum_{i=1}^{N} \ln \left[\sum_{j=1}^{m} \alpha_{i}\left[S\left(s_{j-1} / \boldsymbol{X}_{i}\right)-S\left(s_{i} / \boldsymbol{X}_{i}\right)\right]\right] \\
& I\left(\boldsymbol{\beta}, s_{1} \ldots S_{m-1} / \boldsymbol{X}_{l}\right)=\sum_{i=1}^{N} \ln \left[\sum_{j=1}^{m} \alpha_{i}\left[S_{0}\left(S_{j-1}\right)^{\exp \left(X_{i} \boldsymbol{\beta}\right)}-S_{0}\left(S_{i}\right)^{\exp \left(\boldsymbol{X}_{i} \boldsymbol{\beta}\right)}\right]\right] \\
& I\left(\boldsymbol{\beta}, \gamma_{1} \ldots \gamma_{m-1} / \boldsymbol{X}_{I}\right)=\sum_{i=1}^{N} \ln \sum_{j=1}^{m} \alpha_{i}\left\{\exp \left[-\exp \left(\boldsymbol{X}_{1} \beta\right) \gamma_{1-1}\right]-\exp \left[-\exp \left(\boldsymbol{X}_{1} \beta\right) \gamma_{1}\right]\right\}
\end{aligned}
$$

sendo $\gamma_{j}=-\ln \left[S_{0}\left(s_{j}\right)\right]$, a função de risco acumulada.

Note que, como $S\left(s_{0}\right)=1\left(\gamma_{0}=0\right)$ e $S\left(s_{m}\right)=0\left(\gamma_{m}=\infty\right)$, então (3.19) é função dos parâmetros $\gamma_{j}, j=1, \ldots, m-1$ e $\beta$. Quando os tempos de falha apresentam poucos empates, o número de parâmetros a ser estimado é da ordem do tamanho da amostra, o que ocasiona alguns problemas: (i) Dificuldade na convergência dos processos iterativos, uma vez que o número de parâmetros a ser estimado é grande; (ii) Testes baseados na razão de verossimilhanças não 
podem ser utilizados, uma vez que o número de parâmetros aumenta com o tamanho da amostra.

Diversos autores sugerem algoritmos para estimação da função de sobrevivência em modelos semi-paramétricos na presença de censura intervalar (Huang, 1996; Huang \& Wellner, 1995; Kim, 2003; Lindsey \& Ryan, 1998; Pan, 1999; Pan \& Chapell, 1998). Por sua rapidez e eficiência, o algoritmo ICM (Groeneboom \& Wellner, 1992) será utilizado na obtenção da função de sobrevivência e testes de hipótese serão realizados através de métodos de reamostragem como bootstrap (Efron \& Tibshirani, 1993).

A previsão da função de sobrevivência no ponto $t$, dado um conjunto de variáveis explicativas $X$ se dá pela fórmula:

$$
\hat{S}(t / X)=\hat{S}_{o}(t)^{\exp (x \bar{\beta})}
$$

em que $\widehat{S}_{o}(t)$ é a estimativa não paramétrica da função de sobrevivência basal e $\widehat{\boldsymbol{\beta}}$ é a estimativa de máxima verossimilhança de $\boldsymbol{\beta}$ ambos obtidos através de (3.22).

Utilizando a expressão (3.23) é fácil mostrar que a estimativa do $p$-ésimo quantil da distribuição de sobrevivência condicionada ao vetor de variáveis explicativas $\boldsymbol{X}, \bar{y}_{p}$, é dado por:

$$
\bar{y}_{p}=\bar{W}_{p}^{1 / \exp (x \bar{\beta})}
$$

em que $\widehat{w}_{p}$ é o quantil de ordem $p$ da distribuição basal $\widehat{S} o$.

Serão analisados agora os efeitos das truncagens à direita e à esquerda no modelo de Cox. Suponha que possamos observar a variável aleatória $T$ apenas no intervalo $a<t \leq b$, ou seja, truncada à esquerda pelo valor a e truncada pela direita pelo valor $b$. Seja $S_{T}(t)$ a função de sobrevivência da variável $T$, então, a função de sobrevivência truncada para $T$ é da forma: 


$$
S_{T}(t / a<T \leq b)=\left\{\begin{array}{cl}
0 & \text { para } t \leq a \\
\frac{S_{T}(t)-S_{T}(b)}{S_{T}(a)-S_{T}(b)} & \text { para } a<t \leq b \\
1 & \text { para } t>b
\end{array}\right.
$$

Analogamente, seja $f_{T}(t)$ a função densidade de $T$. Temos que a função densidade truncada é dada por:

$$
f_{T}(t / a<T \leq b)=\left\{\begin{array}{cc}
\frac{f_{T}(t)}{S_{T}(a)-S_{T}(b)} & \text { para } a<t \leq b \\
0 & \text { caso contrário }
\end{array}\right.
$$

Da expressão (3.3), segue que a expressão da função de risco truncada tem a forma:

$$
\lambda_{T}(t / a<T \leq b)=\frac{f_{T}(t / a<T \leq b)}{S_{T}(t / a<T \leq b)}=\frac{f_{T}(t)}{S_{T}(t)-S_{T}(b)}
$$

que não depende de a. Mais detalhes podem ser encontrados em Andersen e colaboradores (1993).

Nota-se pelo desenvolvimento acima que a incorporação da truncagem à esquerda no modelo de Cox não afeta a forma da função de risco, enquanto que a truncagem à direita tende a aumentá-la. A estimação dos parâmetros nesse caso se dá apenas ajustando o grupo de risco no tempo $t_{i}$ pelo seu respectivo valor de truncagem. No caso sem truncagem, o conjunto de risco é monotonicamente decrescente uma vez que, no início do período de acompanhamento, todas as unidades experimentais estão expostas ao risco e esse número tende a diminuir à medida que censuras e falhas vão acontecendo. No caso de truncagem à esquerda o conjunto de risco depende do tempo em que cada indivíduo entra no estudo, podendo ocorrer eventualmente de um grupo exposto ao risco maior no final do experimento do que no início. Como no caso estudado a truncagem à esquerda é constante 
para todos os indivíduos (valores observados sempre maiores que 300 reais), a estimação dos parâmetros não será afetada, pois temos a monotonicidade decrescente do grupo de risco. Contudo, a função de verossimilhança incorporando a truncagem à esquerda é reescrita como a expressão (3.22), substituindo-se agora o parâmetro $\gamma_{j}=-\ln \left[S_{0}\left(s_{j}\right)\right]$ por $\gamma_{j}=-\ln \left[S_{0}\left(s_{j}\right)\right]+\operatorname{In}\left[S_{0}(300)\right]$.

\subsection{Algoritmos de ajuste}

Como nem sempre as expressões das derivadas das funções de verossimilhança têm forma fechada, faz-se necessário o uso de métodos iterativos para obtenção das estimativas de máxima verossimilhança e seus respectivos desvios padrão. Um dos métodos mais conhecidos para a obtenção de raizes de equações não-lineares é o método de Newton-Raphson que será utilizado na obtenção das estimativas no ajuste dos modelos paramétricos. Finkelstein (1986) sugere essa abordagem para o modelo de riscos proporcionais de Cox; contudo, é utilizado o inverso da matriz hessiana em cada iteração, o que gera um custo computacional muito alto uma vez que, para tempos de sobrevivência contínuos e censura intervalar nos modelos semi-paramétricos, o número de parâmetros é da ordem do número de observações. Além disso, é comum que a matriz hessiana esteja próxima da singularidade o que torna difícil sua inversão.

Num contexto mais amplo, Turnbull (1976) apresentou o algoritmo EM (Dempster, et al., 1977) para a obtenção das estimativas não paramétricas de máxima verossimilhança da função de distribuição para dados censurados intervalarmente, sem o uso de covariáveis. Esse algoritmo não necessita do armazenamento e inversão da matriz hessiana. Por outro lado, apresenta uma convergência fraca (Chang, 1990; Wu, 1983) e é de difícil implementação para o modelo de Cox quando o tempo de sobrevivência é continuo (Alioum \& Commenges, 1996). 
Com o intuito de criar um algoritmo mais eficiente, Groeneboom \& Wellner (1992) propuseram o algoritmo ICM, potencialmente mais rápido que o algoritmo EM, e que, além de apresentar convergência global (Aragon \& Eberly, 1992), também apresenta uma relevância prática considerável quando usado em conjunto com métodos de simulação estocástica. Jongbloed (1998) utilizou o algoritmo ICM para estimação não paramétrica da função de sobrevivência para dados censurados à direita (Jongbloed,1998). Pelas vantagens apresentadas, esse algoritmo será utilizado no presente trabalho e uma breve apresentação é desenvolvida a seguir.

O algoritmo ICM foi inicialmente formulado em termos de processos estocásticos e algoritmos de regressão isotônica (Groeneboom \& Wellner, 1992; Huang \& Wellner, 1997), porém será aqui apresentado como uma particularização do método de otimização conhecido como GGP, Generalized Gradient Projection (Bertsekas, 1982; Mangasarian, 1996), com o intuito de estendê-lo ao modelo semi-paramétrico de Cox.

\section{O método GGP}

Suponha que queremos maximizar a função $f(x)$ num conjunto convexo fechado denotado por $\chi$. Seja $\nabla \boldsymbol{f}$ o vetor de primeiras derivadas de $\boldsymbol{f}$ e $\boldsymbol{H}$ uma matriz positiva definida, geralmente tomada como o oposto da matriz Hessiana de $f$, se $f$ é estritamente côncava. O algoritmo GGP atualiza sua estimativa por:

$$
\boldsymbol{X}^{(m+1)}=\operatorname{Proj}\left[\boldsymbol{X}^{(m)}+\boldsymbol{H}^{(m)^{-1}} \nabla \boldsymbol{f}\left(\chi^{(m)}\right), \boldsymbol{H}^{(m)}, \chi\right]
$$

em que Proj é o operador projeção definido por:

$$
\operatorname{Proj}\left[\boldsymbol{x}_{0}, \boldsymbol{H}, \chi\right]=\underset{x}{\arg \min _{x}}\left\{\left(\boldsymbol{x}-\boldsymbol{x}_{0}\right)^{\prime} \boldsymbol{H}\left(\boldsymbol{x}-\boldsymbol{x}_{0}\right): \boldsymbol{x} \in \chi\right\}
$$


Nota-se que, quando $\boldsymbol{H}$ é definida como o oposto da matriz Hessiana de $f$, as expressões acima podem ser interpretadas como as estimativas obtidas através do método de Newton-Raphson sujeitas às restrições do conjunto $\chi$.

\section{O algoritmo ICM}

Adaptando o algoritmo GGP para a maximização da função de verossimilhança do modelo semi-paramétrico de Cox, definimos $\nabla_{1} L(\gamma, \beta)=\partial L(\gamma, \beta) / \partial \gamma$ e $\nabla_{2} L(\gamma, \beta)=\partial L(\gamma, \beta) / \partial \beta$ como sendo os vetores das primeiras derivadas de (3.22); e $G_{1}(\gamma, \beta)=\operatorname{diag}\left(-\partial^{2} L(\gamma, \beta) / \partial \gamma^{2}\right)$ e $G_{2}(\gamma, \beta)=\operatorname{diag}\left(-\partial^{2} L(\gamma, \beta) / \partial \beta^{2}\right)$ correspondendo à diagonal do oposto da matriz Hessiana. O algoritmo ICM atualiza suas estimativas conforme:

$$
\gamma^{(m+1)}=\operatorname{Proj}\left[\gamma^{(m)}+\alpha_{j}^{(m)} G_{1}\left(\gamma^{(m)}, \beta^{(m)}\right)^{-1} \nabla_{1} L\left(\gamma^{(m)}, \beta^{(m)}\right), G_{1}\left(\gamma^{(m)}, \beta^{(m)}\right), \chi\right]
$$

e

$$
\beta^{(m+1)}=\beta^{(m)}+\alpha_{j} G_{2}\left(\gamma^{(m)}, \beta^{(m)}\right)^{-1} \nabla_{2} L\left(\gamma^{(m)}, \beta^{(m)}\right)
$$

sendo $\chi=\left\{\gamma: 0 \leq \gamma_{1} \leq \ldots \leq \gamma_{m-1}\right\}$ e $\alpha_{j}>0$ uma constante com o objetivo de realizar uma convergência mais rápida do algoritmo. Pode ser escolhida como

$$
\alpha_{j}=\max \left\{1 / 2^{i}: L\left(\gamma^{(m+1)}\right)>L\left(\gamma^{(m)}\right), i=0,1,2, \ldots\right\}
$$

que visa tomar um passo mais largo quanto mais distante está a convergência da verossimilhança.

Em particular, definido o conjunto convexo como sendo $\chi=\left\{\gamma: 0 \leq \gamma_{1} \leq \ldots \leq\right.$ $\left.\gamma_{m-1}\right\}$, o operador projeção acima pode ser reescrito como: 


$$
\operatorname{Proj}\left[\boldsymbol{x}_{0}, \boldsymbol{H}, \chi\right]=\min \sum_{i=1}^{\mathrm{D}} h_{i}\left(x_{i}-a_{i}\right)^{2}, \text { sujeito } a x_{i} \leq x_{j} \text { com } i<j
$$

em que $\boldsymbol{H}=\left\{h_{i i}\right\}, \boldsymbol{x}_{0}=\left\{\mathrm{a}_{\mathrm{ii}}\right\}, i=1, \ldots \mathrm{D}$.

Assim, o operador pode ser visto como uma regressão de mínimos quadrados isotônica e é possivel ser resolvido com o algoritmo PAV (pooladjacent-violators), que será brevemente descrito a seguir.

\section{$O$ algoritmo PAV}

Seja o conjunto de dados tridimensional $\left\{x_{i}, a_{i}, h_{i}\right\}$ de tamanho $D$ e denote por $\left\{x_{(i)}, a_{(i)}, h_{(i)}\right\}$ o mesmo conjunto ordenado pela variável $x$. O algoritmo PAV visa encontrar o conjunto $m\left(x_{(i)}\right)$ que minimiza a função $\sum_{i=1}^{D} h_{(i)}\left[m\left(x_{(i)}\right)-a_{(i)}\right]^{2}$ sujeito a $m\left(x_{(1)}\right) \leq m\left(x_{(2)}\right) \leq \ldots \leq m\left(x_{(D)}\right)$.

O algoritmo segue então os seguintes passos:

Para $i=1$,

1) Verificar se as observações $a_{(i)}$ e $a_{(i+1)}$ violam a condição monotônica, ou seja, se $a_{(i)}>a_{(i+1)}$. Se não, incrementar $i$ e repetir passo 1 . Se sim,

2) Substituir $a_{(i)}$ e $a_{(i+1)}$ por sua média ponderada por $h_{(i)}$ e $h_{(i+1)}$ pela fórmula

$$
a^{*}{ }_{(i)}=\left(h_{(i)} a_{(i)}+h_{(i+1)} a_{(i+1)}\right) /\left(h_{(i)}+h_{(i+1)}\right)
$$

3) Verificar se $a_{(i-1)}>a^{*}{ }_{(i)}$. Se sim, substituir $a_{(i-1)}, a_{(i)}$ e $a_{(i+1)}$ pela sua média ponderada e retornar ao passo 3 . Caso contrário, incrementar $i$ e voltar ao passo 1.

Mais detalhes sobre esse algoritmo pode ser encontrado em Robertson, Wrigth \& Dykstra (1998). 


\subsection{Adaptações da metodologia}

A metodologia descrita anteriormente foi desenvolvida com o objetivo de possibilitar o estudo da relação entre variáveis explicativas e o tempo de sobrevivência (ou de falha) de certo fenômeno de interesse. A proposta inovadora dessa dissertação é estudar a relação entre as variáveis explicativas e a renda de clientes, em substituição ao tempo de sobrevivência. Desta forma, existem algumas questões conceituais que necessitam maior discussão.

Assim como o tempo, renda é uma variável estritamente positiva e com distribuição geralmente assimétrica, o que motivou o uso das técnicas já conhecidas para estudá-la como, por exemplo, os modelos de sobrevivência paramétricos com distribuição Gama ou Weibull e o modelo semi-paramétrico de Cox.

Uma importante suposição na construção estatistica dos modelos é que o mecanismo de censura é não informativo e independente, isto é, (i) a distribuição das censuras são independentes entre si, (ii) a distribuição das censuras é independente da distribuição dos tempos de falha e (iii) as variáveis explicativas não estão relacionadas com os parâmetros das distribuições das censuras. No caso da distribuição da renda, as distribuições da renda declarada e da renda comprovada são os fatores que definem as censuras. Assim, é suposto (i) que a distribuição da renda declarada e da renda comprovada são independentes para esse público estudado, (ii) que o fato de conhecermos a renda real de um cliente independe do valor da sua renda comprovada ou declarada e, por fim (iii) que a renda declarada não é correlacionada com as variáveis explicativas, pois o cliente pode mentir quando declara a renda independente de seu perfil.

Duas das funções com maior apelo interpretativo nos modelos de sobrevivência são as funções de sobrevivência e a função de risco. A interpretação da função de sobrevivência nesse novo contexto é imediata de modo que $S(t)=p$ significa agora que a probabilidade de que a renda mensal 
real do cliente ultrapassar $t$ é $p$. Já para a interpretação da função de risco, lembramos que o cliente apresenta uma falha se ele consegue comprovar sua renda na integra, ou seja, sua renda declarada é igual à comprovada. São clientes que acreditamos possuir o valor da verdadeira renda mensal. Assim, podemos interpretar a função de risco $h(t)$ como sendo o risco do cliente conseguir comprovar sua renda na integra ou ainda o risco de conhecermos o valor real da renda. 


\section{Aplicação}

Nesse capítulo são apresentados os resultados das modelagens paramétrica e semi-paramétrica apresentadas no Capitulo 3. A base de dados descrita no Capítulo 2 foi utilizada para ilustrar a metodologia proposta.

\subsection{Tratamento dos dados}

Antes do ajuste dos modelos, são necessárias algumas considerações a respeito da construção das variáveis explicativas de modo a obter resultados mais robustos e confiáveis, tendo em vista a estabilidade dos parâmetros em relação ao tempo.

\subsubsection{Categorização das variáveis}

Parte das variáveis coletadas para o estudo tem natureza discreta com um grande número de categorias. O agrupamento dessas variáveis em um número menor de categorias apresenta algumas vantagens. A redução do número de categorias leva a uma redução no número de parâmetros a ser estimado no modelo, o que ajuda no processo de estimação. Outra vantagem é que algumas categorias possuem um número muito pequeno de observações prejudicando assim inferências a respeito da mesma. Agrupando-as, podem-se obter resultados mais robustos. 
No caso de variáveis contínuas, a categorização pode ocasionar perda de informação, porém apresenta também algumas vantagens. São raras as vezes em que a variável explicativa apresenta uma relação linear com o tempo de falha (ou com o seu logaritmo). Desta forma, a categorização da variável pode se tornar útil para contornar esse problema. Outra vantagem é a redução da influência de pontos aberrantes da variável explicativa na estimação dos parâmetros da regressão.

Para iniciar o procedimento de categorização das variáveis contínuas, é necessária uma preparação inicial. Todas as variáveis foram categorizadas de acordo com os percentis a cada $5 \%$, de modo a formar 20 categorias. Feito isso, um modelo de regressão paramétrico utilizando a distribuição Gama Generalizada foi ajustado aos dados, utilizando como resposta as rendas comprovada e declarada e como variável explicativa a variável a ser categorizada. A distribuição Gama Generalizada foi utilizada por apresentar uma grande versatilidade em suas funções de distribuição, tendo outras distribuições conhecidas como caso particular. Maiores detalhes serão discutidos na Seção 4.2.1. Categorias com estimativas dos parâmetros próximas foram agrupadas e então foi ajustada uma nova regressão. O procedimento foi repetido até se obter um resultado que discrimine bem as categorias remanescentes. Um procedimento análogo foi usado para o agrupamento das categorias das variáveis discretas.

\subsubsection{Consolidação longitudinal}

Algumas variáveis comportamentais foram coletadas com um histórico de cinco meses, a fim de evitar conclusões pontuais. Para esses casos foi criado um indice de consolidação dessas variáveis no tempo de forma a priorizar dois fatores:

(i) A distância de tempo entre a mensuração da variável e a coleta da amostra. Observações mais recentes devem ter maior peso no indice. 
(ii) A variabilidade entre os valores mensurados em relação ao tempo. $O$ indice deve refletir a variabilidade dos valores medidos para um mesmo indivíduo.

Com relação a (i), será utilizada uma média ponderada dos valores com peso inversamente proporcional à distância da medida em relação ao período de amostra. Quanto mais antiga a observação, menor o peso no índice final. Os pesos utilizados foram $0.3,0.25,0.2,0.15,0.1$ para os valores mensurados nos meses atual $(m)$, anterior $(m-1), 2$ meses atrás $(m-2), 3$ meses atrás $(m-3)$ e 4 meses atrás $(m-4)$ respectivamente.

Com o intuito de incorporar a variabilidade das observações no índice, utilizou-se uma medida de variabilidade para que penalizasse a média ponderada em função da variabilidade mensal. Na Tabela 4.1 temos a comparação de três medidas concorrentes de variabilidade para os dados. A primeira é a variância, a segunda o coeficiente de variação e, por fim, a medida sugerida nesse trabalho, chamada aqui de $M V$ e que é dada pela razão da variância pela média. Nota-se que o coeficiente de variação não é uma medida adequada, pois ela desconsidera a magnitude dos valores envolvidos. Nas duas primeiras linhas da tabela, um cliente com gasto de $R \$ 1.000,00$ e outro com gasto de $\mathrm{R} \$ 10,00$ tem o mesmo coeficiente de variação. Outra desvantagem apresentada por essa medida, e que também é uma propriedade da variância, pode ser observada nas duas últimas linhas da tabela. Um cliente com três gastos de $\mathrm{R} \$ 1.000,00$ tem a mesma medida de um cliente com apenas dois gastos de $R \$ 1.000,00$. Desta forma, a medida $M V$ torna-se a mais adequada para a criação do índice pois leva em conta tanto a magnitude dos valores quanto a constância em relação ao tempo.

\begin{tabular}{|c|c|c|c|c|c|c|c|}
\hline \multicolumn{5}{|c|}{ Lançamentos de débito no mês } & \multirow{2}{*}{ Variância } & \multirow{2}{*}{$\begin{array}{l}\text { coeficiente } \\
\text { de variação }\end{array}$} & \multirow{2}{*}{ MV } \\
\hline$n-4$ & $\mathrm{n}-\mathbf{3}$ & $\mathrm{n}-2$ & $n-1$ & $\mathbf{n}$ & & & \\
\hline $\mathrm{R} \$ 10$ & $\mathrm{R} \$ 0$ & $\mathrm{R} \$ 0$ & $\mathrm{R} \$ 0$ & $\mathrm{R} \$ 10$ & 24 & 1 & 6,00 \\
\hline$R \$ 1.000$ & $\mathrm{R} \$ 0$ & $\mathrm{R} \$ 0$ & $\mathrm{R} \$ 0$ & $\mathrm{R} \$ 1.000$ & 240.000 & 1 & 600,00 \\
\hline$R \$ 1.000$ & $\mathrm{R} \$ 0$ & $\mathrm{R} \$ 1.000$ & $\mathrm{R} \$ 0$ & $\mathrm{R} \$ 1.000$ & 240.000 & 1 & 400,00 \\
\hline
\end{tabular}

Tabela 4.1: Comparação das medidas de variabilidade 
Escolhida a medida de variabilidade, é calculado o índice de consolidação longitudinal (ICL) segundo a fórmula:

$$
I C L=\frac{M_{p}}{F P(M V)}
$$

em que $M_{p}$ é a média ponderada das observações, $F P$ é a função de penalização e $M V$ a medida de variabilidade dado por:

$$
M V=\frac{\operatorname{Var}(\boldsymbol{x})}{M(\boldsymbol{x})}
$$

Aqui, $\boldsymbol{x}$ é o vetor dos dados, $M(x)$ e $\operatorname{Var}(\boldsymbol{x})$ são a média e a variância dos dados, respectivamente.

A função de penalização $(F P)$ escolhida foi:

$$
F P(x)=2-\exp (-x / k)
$$

sendo $k$ o parâmetro de escala. Essa função foi escolhida por ser monotonicamente crescente e ter limitante superior igual a 2 .

O gráfico abaixo exemplifica como o fator de penalização será atribuido, de acordo com o coeficiente $M V$. Quanto maior o valor de $k$, menos agressiva será a penalização, sempre limitando à metade da média ponderada. $\mathrm{O}$ valor do parâmetro de escala escolhido foi 3.000 , pois apresenta uma velocidade de crescimento razoável, dada a magnitude dos índices $M V$ calculados na base estudada. 


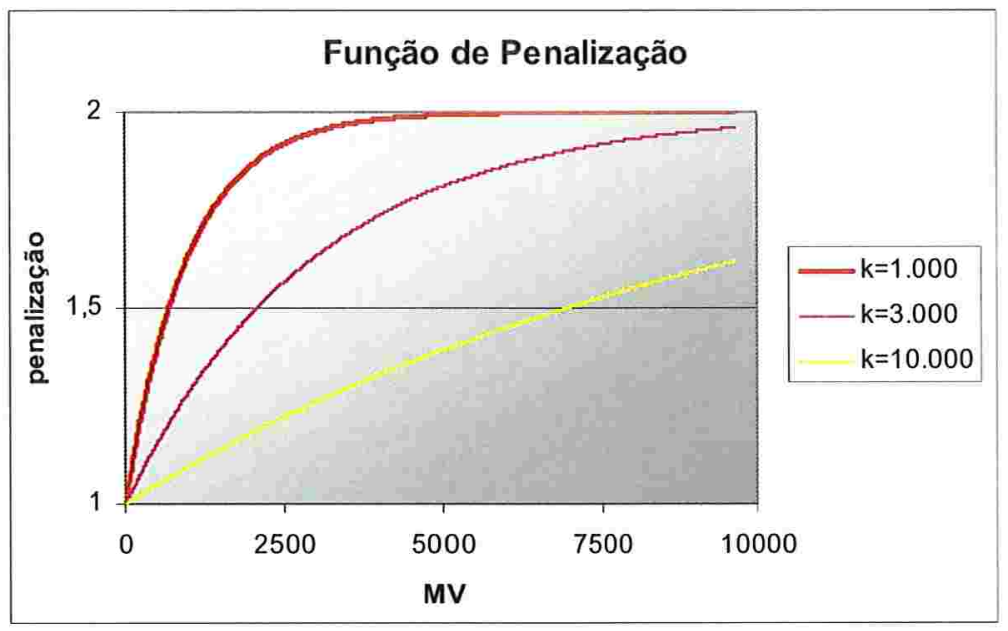

Gráfico 4.1: Efeito do parâmetro na função de penalização.

A Tabela 4.2 exemplifica a criação do índice para a variável valor total de lançamentos de débito. Nos primeiros dois casos apresentados, é possível notar o efeito da distância do tempo no índice. O índice $I C L$ relativo ao gasto de $\mathrm{R} \$ 1.000,00$ a quatro meses atrás é inferior ao mesmo índice calculado relativo ao mesmo gasto no mês atual. Nos últimos casos observa-se que, apesar das situações apresentarem mesmo valor da média ponderada, o valor do índice varia de acordo com a variabilidade entre os meses.

\begin{tabular}{|c|c|c|c|c|c|c|c|c|}
\hline \multicolumn{5}{|c|}{ Lançamentos de débito no mês } & \multirow{2}{*}{ MV } & \multirow{2}{*}{$\begin{array}{c}\text { média } \\
\text { ponderada }\end{array}$} & \multirow{2}{*}{ penalização } & \multirow{2}{*}{$\begin{array}{c}\text { indice } \\
\mathrm{ICL} \\
\end{array}$} \\
\hline$n-4$ & $n-3$ & $n-2$ & $n-1$ & $\mathrm{n}$ & & & & \\
\hline $\mathrm{R} \$ 1.000$ & $\mathrm{R} \$ 0$ & R\$O & $\mathrm{R} \$ 0$ & $\bar{R} \$ 0$ & 800 & 100 & 1,23 & 81,03 \\
\hline $\mathrm{R} \$ 0$ & $\mathrm{R} \$ 0$ & $\mathrm{R} \$ 0$ & $\mathrm{R} \$ 0$ & $\mathrm{R} \$ 1.000$ & 800 & 300 & 1,23 & 243,10 \\
\hline $\mathrm{R} \$ 7.500$ & $\mathrm{R} \$ 0$ & $\mathrm{R} \$ 7.500$ & $\mathrm{R} \$ 0$ & $\mathrm{R} \$ 7.500$ & 3.000 & 4.500 & 1,63 & $2.757,15$ \\
\hline$R \$ 2.400$ & $\mathrm{R} \$ 7.200$ & $\mathrm{R} \$ 6.600$ & $\mathrm{R} \$ 4.200$ & $\mathrm{R} \$ 2.700$ & 838 & 4.500 & 1,24 & $3.617,88$ \\
\hline$R \$ 4.500$ & $R \$ 4.500$ & $R \$ 4.500$ & $R \$ 4.500$ & $R \$ 4.500$ & 0 & 4.500 & 1,00 & $4.500,00$ \\
\hline
\end{tabular}

Tabela 4.2: Exemplo de utilização do índice $I C L$.

\subsection{Ajuste dos modelos}

O banco de dados para o ajuste do modelo é constituído de 3020 observações e 154 variáveis dicotômicas após preparo. Duas abordagens vão 
ser discutidas nas próximas seções: o ajuste do modelo paramétrico, utilizando a distribuição gama generalizada, e o ajuste do modelo semi-paramétrico de Cox.

Para ambas as abordagens, foram construidos programas em SAS (v. 8.2) para o ajuste dos modelos devido à ausência de algoritmos já desenvolvidos. Os programas estão dispostos na íntegra no Apêndice B.

O método de seleção de variáveis será feito manualmente, primeiramente pela não disponibilidade desses algoritmos nos softwares mais populares e também para um maior controle das variáveis utilizadas, a fim de melhorar a interpretabilidade do modelo final.

\subsubsection{Ajuste do modelo paramétrico}

Primeiramente, vamos supor a distribuição Gama Generalizada para a distribuição basal por ser uma distribuição versátil, tendo outras distribuições como caso particular. O Gráfico 4.2 ilustra essa versatilidade.

A função densidade de probabilidades (FDP) da distribuição Gama Generalizada é:

$$
g(t)=\frac{|\delta|}{\operatorname{t\sigma } \Gamma\left(\delta^{-2}\right)}\left(\delta^{-2} v^{\delta}\right)^{\delta^{-2}} \exp \left(-v^{\delta} \delta^{-2}\right) \quad \operatorname{com}-\infty<\delta<\infty \text { e } \sigma>0
$$

em que $v=\exp \left(\frac{\log (t)-\mu}{\sigma}\right), \mu$ é o parâmetro de locação, $\sigma$ é o parâmetro de escala e $\delta$ é o parâmetro de forma. 


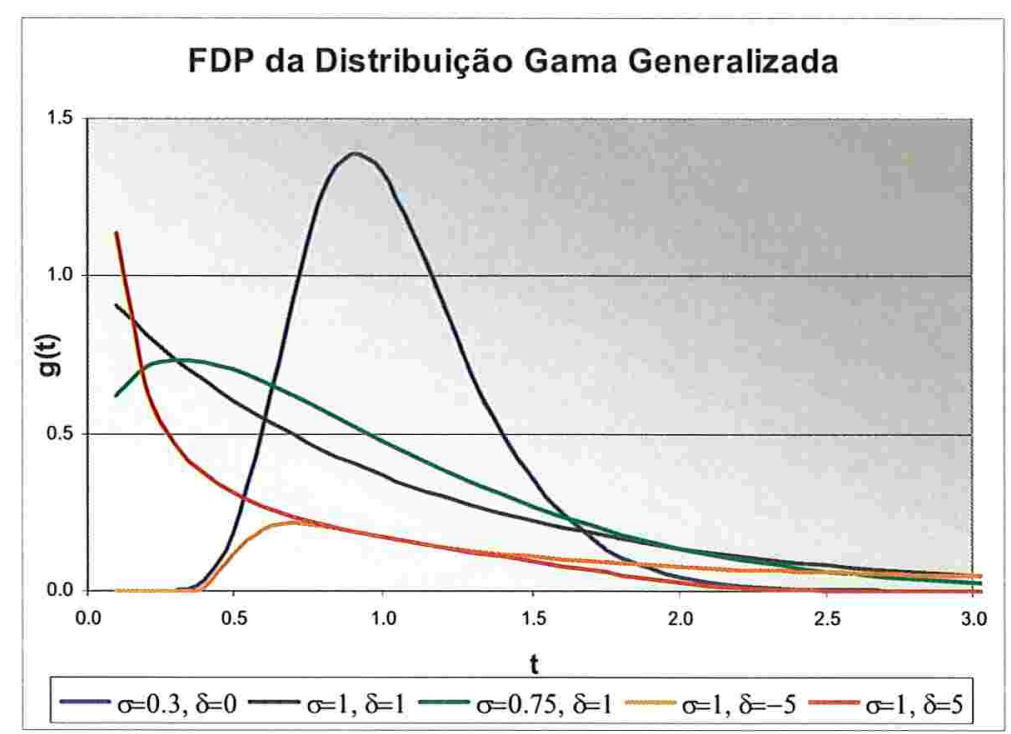

Gráfico 4.2: Distribuição Gama Generalizada $(\mu=0)$.

Pode-se mostrar que tomando $\delta=0$ temos, como caso particular, a distribuição log-normal. Com $\delta=1$ obtemos a distribuição Weibull e com $\delta=1 \mathrm{e}$ $\sigma=1$ obtemos a distribuição exponencial.

Usualmente, em modelos paramétricos aplica-se o logaritmo neperiano na variável resposta com o intuito de melhorar a eficiência dos algoritmos e facilitar a interpretação. Desta forma, a função implementada no algoritmo de ajuste é a Valor Extremo Generalizado.

Se uma variável aleatória $T$ tem distribuição Gama Generalizada, então $Y=\log (T)$ tem distribuição Valor Extremo Generalizado, cuja função densidade de probabilidade é dada por:

$$
f(t)=\frac{|\delta|}{\sigma \Gamma\left(\delta^{-2}\right)}\left(\delta^{-2} \exp (\delta u)\right)^{\delta^{-2}} \exp \left(-\exp (\delta u) \delta^{-2}\right)
$$

sendo $u=\frac{t-\mu}{\sigma}$.

Primeiramente foi ajustado um modelo com todas as variáveis explicativas; então, foram retiradas as variáveis não significantes a um nível de $10 \%$ e ajustado outro modelo, até que todas as variáveis fossem significativas. Foi 
também ajustado um modelo desconsiderando a truncagem a fim de avaliar os efeitos de não introduzir essa característica na estimação. Na Tabela A.2 do Apêndice A pode-se fazer a comparação das estimativas dos dois modelos. As estimativas dos parâmetros referentes às variáveis explicativas são pouco sensiveis ao fato de desconsiderar a truncagem no ajuste do modelo, assim como a estimativa do parâmetro de escala da distribuição basal. Contudo, nota-se que a estimativa do parâmetro de forma sofre variação. As estimativas intervalares de $95 \%$ do parâmetro de forma do modelo considerando e desconsiderando a truncagem são, respectivamente $[0.89 ; 1.26]$ e $[0.66 ; 0.94]$. Concluí-se que, considerando a truncagem no modelo, é possível reduzi-lo a distribuição Weibull, pois o intervalo de confiança engloba o 1 , fato esse que não ocorre quando desconsiderada a truncagem.

Assim, um novo modelo foi ajustado utilizando a distribuição Weibull. As estimativas finais dos parâmetros encontram-se na Tabela A.3.

O Gráfico 4.3 mostra a forma da distribuição basal ajustada pelo modelo Weibull (substituindo o valor do parâmetro de forma estimado e com parâmetro de escala igual a 1). É importante ressaltar que ela vem ao encontro do que esperamos de uma distribuição de renda no que se refere a uma forte assimetria à esquerda.

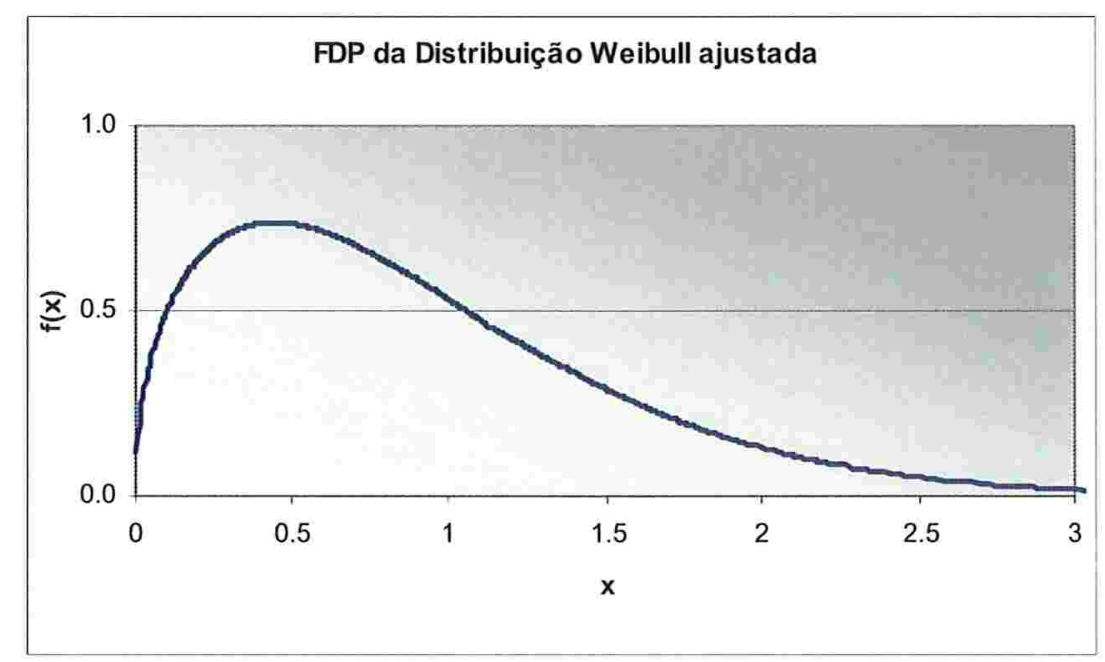

Gráfico 4.3: Distribuição Weibull ( $\sigma=1$ e $\delta=0.69)$. 
Como o modelo Weibull é um modelo de riscos proporcionais, torna-se interessante a comparação de seu desempenho com o modelo de riscos proporcionais de Cox, que será considerado na próxima seção.

\subsubsection{Ajuste do modelo semi-paramétrico}

Utilizando os programas do Apêndice $B$, foi ajustado o modelo semiparamétrico de Cox utilizando o algoritmo ICM (Groeneboom \& Wellner, 1992). Foram utilizadas as mesmas variáveis selecionadas pelo modelo paramétrico, a fim de tornar a comparação mais direta. As estimativas dos parâmetros obtidas na modelagem estão dispostas na Tabela A.4.

É interessante destacar que no modelo semi-paramétrico não há a necessidade de incluir o termo do intercepto como no modelo paramétrico. Isso se deve ao fato de que, segundo a parametrização dicotômica escolhida para categorização das variáveis explicativas, no modelo paramétrico o intercepto faz o papel do parâmetro de escala da distribuição basal enquanto que no modelo semi-paramétrico essa distribuição será estimada por métodos não paramétricos não necessitando assim de parâmetros adicionais.

Para a obtenção das estimativas dos erros padrão, foi utilizada a técnica Bootstrap (Efron \& Tibshirani, 1993). Os seguintes passos foram utilizados:

1) Uma amostra com reposição da base de estudo de mesmo tamanho foi gerada (3020 observações).

2) O modelo foi ajustado novamente e as estimativas obtidas foram armazenadas.

3) Os passos 1 e 2 foram repetidos por $B$ vezes.

4) Os desvios padrão das estimativas dos parâmetros simulados foram calculados empiricamente.

Desta forma, obtem-se uma estimativa para os desvios padrões das estimativas baseando-se em B $=300$ amostras bootstrap.

Devido à diferente parametrização, a interpretação dos parâmetros no modelo de Cox difere da interpretação dos parâmetros nos modelos 
paramétricos o que gera uma drástica diferença nas estimativas dos modelos, diferindo inclusive no sinal. Por exemplo, analisando a variável sexo nos dois modelos, temos que a estimativa para o sexo masculino no modelo paramétrico é de 0.15 e no modelo de Cox é - 0.16 . No primeiro caso, interpretamos que renda para um homem é cerca de $16 \%(\exp (0.15)=1.16)$ maior que para uma mulher com o mesmo perfil. No caso do modelo de Cox, temos que o risco de um homem conseguir comprovar sua renda na integra é cerca de $14 \%(\exp (-0.16)=0.86)$ menor do que uma mulher com o mesmo perfil.

\subsection{Diagnóstico}

A análise de diagnóstico é uma ferramenta usada para validar as suposições feitas de antemão e para encontrar pontos influentes nas estimativas dos parâmetros. Em modelos de regressão em geral, é comum a construção de resíduos baseados na diferença entre valor predito e o valor estimado pelo modelo. Porém, indices baseados em assertividade em análise de sobrevivência são inaplicáveis, uma vez que não conhecemos o valor exato da variável resposta, nem possuímos um único valor predito e sim uma função de probabilidades.

No caso de censuras à direita, várias são as propostas de resíduos para verificação da adequação do modelo. Um dos resíduos mais utilizados em modelos paramétricos é o resíduo de Cox-Snell (Cox \& Snell, 1968), que fornece uma informação de qualidade geral do ajuste. Outros resíduos comumente utilizados nos modelos semi-paramétricos para verificação de pontos influentes, forma da função que relaciona as variáveis explicativas ao tempo de sobrevivência e proporcionalidade dos riscos são os resíduos martingais (Lagakos et al., 1980), resíduos do desvio (Therneau et al., 1990) e os resíduos de Schoenfeld (Schoenfeld,1982). 
Contudo, são necessárias adaptações nesses resíduos para o caso de censura intervalar (Farrington, 2000). Na abordagem semi-paramétrica, o problema é ainda mais complicado pelo fato do número de parâmetros crescer com o tamanho da amostra. Nesse caso, as adaptações feitas pelo autor não são aplicáveis.

Desta forma, será considerada apenas uma análise de adequação geral dos modelos. Para tanto, será utilizado o resíduo de Cox-Snell, que se baseia no fato de que, se o modelo imposto for verdadeiro, $-\log (\hat{S}(t))$ tem distribuição exponencial com média unitária, sendo que $\widehat{S}(t)$ é a função de sobrevivência estimada pelo modelo em questão. No entanto, como os dados são censurados intervalarmente, os resíduos também o serão, de forma que teremos uma amostra censurada intervalarmente de uma exponencial com média 1.

Lembrando que a função de sobrevivência da distribuição exponencial com média 1 tem a forma $S(t)=\exp [-t]$, é fácil concluir que, denotando $\hat{S}_{R}(t)$ a estimativa da função de sobrevivência dos resíduos e supondo o modelo bem ajustado, o gráfico de $-\log \left(\widehat{S}_{R}(t)\right)$ contra o $t$ deve ser próximo a uma reta com inclinação $45^{\circ}$, passando pela origem.

Como os resíduos também são variáveis aleatórias censuradas, foi usada uma estimativa não paramétrica de sua função de sobrevivência para verificar se a distribuição se assemelha a uma exponencial com média 1.

Calculando então os resíduos de Cox-Snell, o método descrito na Seção 3.3.1 foi utilizado para estimativa não paramétrica de sua função de sobrevivência. Obtendo as estimativas e plotando o gráfico sugerido acima, tanto para o modelo paramétrico como para o semi-paramétrico, nota-se que os modelos parecem estar bem ajustados apesar do pequeno desvio a partir de $t>4$. Portanto, conclui-se que não há fortes evidências de fuga das suposições feitas. 


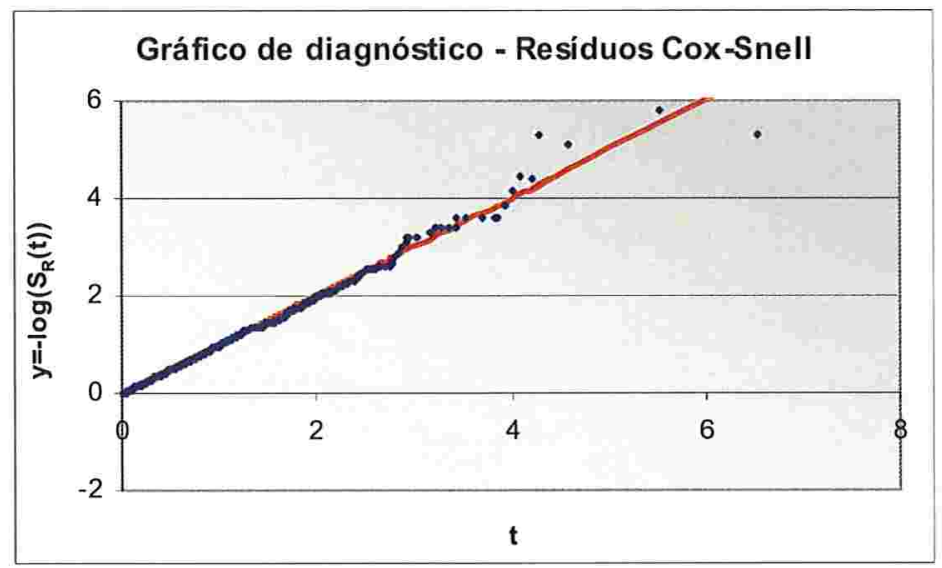

Gráfico 4.4:Avaliação do ajuste para o modelo Weibull.

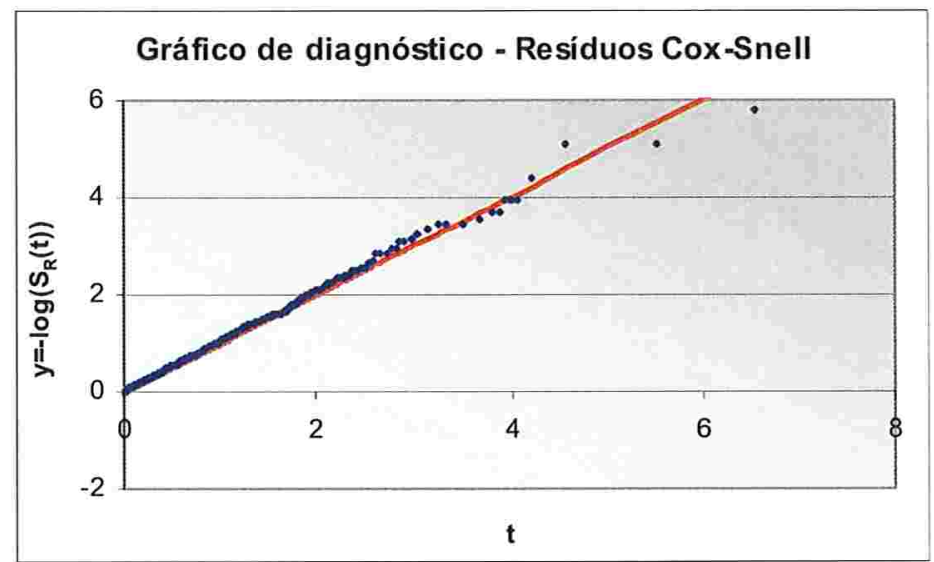

Gráfico 4.5: Avaliação do ajuste para o modelo de Cox.

\subsection{Comparação de desempenho}

Para a comparação de desempenho, é necessário inicialmente definir o modo como os resultados obtidos pelos modelos serão empregados na prática. É interessante, por exemplo, que conheçamos a função de sobrevivência estimada no ponto superior do intervalo de censura para os clientes censurados intervalarmente e para os clientes censurados à esquerda. Dessa forma, podemos saber a probabilidade do cliente ganhar mais do que aquilo 
que ele declara. Para clientes com censura à direita é interessante conhecer, por exemplo, um quantil de ordem $p$ (quanto menor $p$ mais conservadora será a política) de sua respectiva função de sobrevivência. Se sua renda estiver muito aquém desse valor podemos aumentá-la automaticamente sem que seja necessária uma intervenção do cliente. As macros de estimação dos modelos paramétricos e do modelo semi-paramétrico dispostas no Apêndice B estão preparadas tanto para estimação da função de sobrevivência para cada cliente como para do $p$-ésimo quantil da correspondente distribuição de sobrevivência. Com o intuito de observar o comportamento dos modelos na predição, foi estimada, para todos os clientes, a renda mediana e foi calculada a média dessas rendas para cada variável explicativa nos dois modelos. Para efeito de comparação, foi calculada também a renda média para clientes não censurados cujo verdadeiro valor da renda é conhecịdo. Os dados estão dispostos na Tabela A.5. Pode-se notar que os valores estão bem próximos um do outro, tanto na comparação dos modelos quanto dos valores observados na amostra para os não censurados. Nota-se que, geralmente, os valores preditos pelos modelos tendem a ser maiores do que os observados. Esse fato deve-se provavelmente ao número elevado de censuras à direita, o que tende a superestimar as predições.

Apesar do modelo semi-paramétrico possuir muito mais parâmetros que o modelo paramétrico, o tempo de processamento é muito menor, o que se deve à eficiência do algoritmo ICM.

Os modelos apresentaram resultados muito semelhantes, porém é interessante notar que a forma da função de risco basal ajustada pelo modelo de Cox difere em sua forma daquela ajustada para a distribuição Weibull como mostra o Gráfico 4.5. 


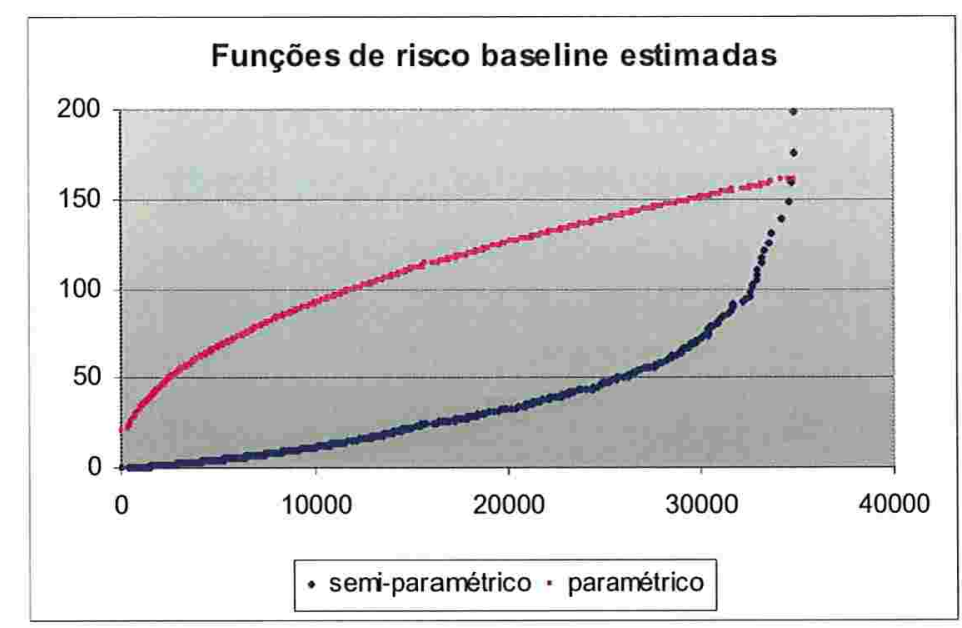

Gráfico 4.5:Funções de risco ajustadas pelo modelo de Cox e Weibull.

Como os modelos apresentam resultados muito parecidos, o modelo paramétrico é preferível nesse caso por diversos motivos: de mais fácil implementação sistêmica uma vez que possui uma forma paramétrica para a função de sobrevivência; é possível realizar testes de hipóteses nos parâmetros e por fim, possibilita estimativas intervalares para os quantis estimados sem utilizar métodos de simulação estocástica. É importante frisar também que a abordagem paramétrica é mais precisa e possui testes mais poderosos do que a abordagem semi-paramétrica uma vez que a verdadeira distribuição dos dados é adequadamente modelada (Lima, 1988). 


\section{Considerações finais}

Neste trabalho, foi utilizada uma modelagem baseada na metodologia para dados de sobrevivência com o intuito de se estudar o rendimento mensal de clientes de uma instituição credora, com base em seu perfil e comportamento.

Foram apresentadas duas abordagens: paramétrica e semi-paramétrica. Em resultados práticos, as duas abordagens comportam-se de maneira muito parecida; contudo, deve ser salientado que, para cada estudo deve-se escolher qual abordagem e qual distribuição melhor se adequa à população a ser estudada. O modelo paramétrico utilizado foi baseado na distribuição Weibull, pela maior facilidade de implementação sistêmica. Contudo, considerações usualmente empregadas em dados de sobrevivência para a escolha de um modelo adequado podem ser utilizados, contanto que possam acomodar a complexidade presente nos dados analisados (censuras e truncagens). Este ponto pode, eventualmente, colocar o modelo de Cox em perspectiva mais favorável de uso.

Os algoritmos implementados no procedimento IML do SAS (v8.2) não foram otimizados em relação ao tempo de processamento, podendo demandar um tempo consideravelmente alto para estimação dos parâmetros, dependendo do tamanho da amostra e do número de variáveis explicativas utilizadas. Entretanto, várias técnicas de otimização devem melhorar a performance das rotinas.

Um algoritmo alternativo ao ICM para estimação dos parâmetros no modelo semi-paramétrico foi sugerido por Wellner \& Zhan (1997), que se baseia em um procedimento iterativo híbrido utilizando os algoritmos EM e ICM, de forma a diminuir o tempo de processamento. Segundo o trabalho, o algoritmo 
sugerido é mais eficiente que o EM e o ICM isoladamente, especialmente quando o banco de dados apresenta censuras à direita, à esquerda e intervalar. O algoritmo também apresenta convergência global o que o torna uma boa alternativa para o problema proposto.

Pode ser interessante que o modelo gere uma estimativa do percentil de ordem $p$ como um valor predito da renda de um cliente com determinado perfil, por exemplo. Um importante caso particular seria a mediana $(p=1 / 2)$. A escolha do valor de $p$ é, na verdade, uma questão de estratégia de negócio, de forma que não foi feita nenhuma sugestão de qual o melhor percentil a ser utilizado. Os programas implementados estão preparados para estimação de qualquer percentil desejado.

$\mathrm{Na}$ modelagem realizada, as variáveis continuas foram categorizadas. Entretanto, este procedimento pode atenuar o poder preditivo do modelo. Portanto, pode ser interessante avaliar o uso das variáveis quantitativas em seu estado natural contanto que seja previamente feito uma avaliação de sua forma funcional no modelo, bem como a presença de valores aberrantes.

Acredita-se que a variável renda mensal esteja altamente relacionada com a capacidade de pagamento do cliente, o que faz com que essa seja uma informação atraente para ser incluída em modelos de mensuração de risco de crédito, como os citados na seção 1.1. Contudo, devido à incerteza em sua mensuração, essa informação por diversas vezes é desprezada. Desta forma, os modelos sugeridos no presente trabalho podem ser utilizados para uma melhor inferência a respeito dessa renda e assim utilizá-la como uma variável de entrada em modelos já conhecidos, melhorando possivelmente o poder preditivo dos mesmos.

Outra abordagem que pode ser interessante é o uso de variáveis explicativas dependentes no tempo (Fisher \& Lin, 1999). A princípio, seria interessante em estudos de longa duração, considerar a possibilidade de mudanças para algumas variáveis comportamentais à medida que a renda de um determinado cliente evolui, possibilitando um modelo de previsão mais eficiente. 
A análise de diagnóstico do modelo de Cox na presença de censura intervalar e truncagem com variável resposta contínua é muito pouco estudada na literatura, assim como os testes de hipóteses relacionados aos parâmetros estimados pelo modelo e à verificação de suposições como a de riscos proporcionais. O uso do resíduo de Cox-Snell também sofre algumas críticas quando utilizado na abordagem semi-paramétrica (Klein \& Moeschberger, 1997). Desta forma, métodos diagnósticos para o problema tratado nesse trabalho representam uma área promissora para estudos futuros. 
6. Apêndices 


\subsection{Apêndice A - Tabelas}

Tabela A.1: Variáveis explicativas disponiveis para o estudo

\section{Variáveis Cadastrais}

- Sexo

- idade

- Grau de instrução

- Tipo do imóvel residencial

- Estado civil

- Quantidade de veículos

- Segmento

- Patrimônio

- CEP comercial

- Tempo de emprego

- CEP residencial

- Tempo de conta

- Profissằo

Variáveis Comportamentais

Consolidação

\begin{tabular}{ll}
\hline Saldo médio credor & Soma \\
\hline Saldo médio devedor & Soma \\
\hline Quantidade de lançamentos de crédito & Soma \\
\hline Quantidade de lançamentos de débito & Soma \\
\hline Quantidade de compensações & Soma \\
\hline Quantidade de dias em excesso no limite & Máximo \\
\hline Valor do limite da conta investimento & Máximo \\
\hline Índice de rentabilidade do cliente (IRC) & - \\
\hline Quantidade de acordos & Soma \\
\hline Behavior scoring do cheque especial & Pior \\
\hline Valor do limite de cheque especial & Máximo \\
\hline Saldo médio devedor do cheque especial & Máximo \\
\hline Índice de utilização do cheque especial & Máximo \\
\hline Quantidade de dias em atraso em produtos & Máximo \\
parcelados & \\
\hline
\end{tabular}




\begin{tabular}{|c|c|}
\hline Valor emprestado em empréstimo pessoal & Soma \\
\hline $\begin{array}{l}\text { Valor emprestado em financiamento de } \\
\text { veículos }\end{array}$ & Soma \\
\hline Valor gasto em cartão de crédito & Soma \\
\hline Percentual do rotativo utilizado & Máximo \\
\hline Valor do limite de crédito no cartão & Máximo \\
\hline Behavior scoring do cartão de crédito & Pior \\
\hline Indicador de proteção máxima no cartão & Soma \\
\hline IRC em conta corrente & Soma \\
\hline IRC em poupança & Soma \\
\hline IRC em financiamentos & Soma \\
\hline IRC em cobrança & Soma \\
\hline IRC em fundos & Soma \\
\hline IRC em seguros e previdência & Soma \\
\hline IRC em aplicações & Soma \\
\hline IRC em cartão de crédito & Soma \\
\hline $\begin{array}{l}\text { Valor total de lançamentos de débito } \\
\text { automático }\end{array}$ & Soma \\
\hline $\begin{array}{l}\text { Valor total de pagamentos de água, luz e } \\
\text { telefone }\end{array}$ & Soma \\
\hline $\begin{array}{l}\text { Valor total de pagamentos de assinaturas de } \\
\text { jornal, revista, internet, escolas, clubes, etc }\end{array}$ & Soma \\
\hline $\begin{array}{l}\text { Valor total de lançamentos de ficha de } \\
\text { compensação/contas a pagar }\end{array}$ & Soma \\
\hline $\begin{array}{l}\text { Valor total de lançamentos de seguros de } \\
\text { vida, casa, previdência, saúde etc }\end{array}$ & Soma \\
\hline Valor total de lançamentos de saques & Soma \\
\hline $\begin{array}{l}\text { Valor total de lançamentos de cartões de } \\
\text { crédito }\end{array}$ & Soma \\
\hline Valor total de lançamentos de aplicações & Soma \\
\hline
\end{tabular}


Valor total de lançamentos de débito de Soma financiamento, leasing, consórcio

Valor total de lançamentos de crédito de Soma financiamento, leasing, consórcio

Valor total de lançamentos de cheques Soma compensados

Valor total de lançamentos de depósito Soma /crédito

\begin{tabular}{lc}
\hline $\begin{array}{l}\text { Valor total de lançamentos de crédito de } \\
\text { salário }\end{array}$ & Soma \\
\hline $\begin{array}{l}\text { Valor total de lançamentos de crédito de } \\
\text { cheques devolvidos }\end{array}$ & Soma \\
\hline Valor total de lançamentos de débito de & Soma \\
cheques devolvidos & Soma \\
\hline $\begin{array}{l}\text { Valor total de lançamentos de crédito de } \\
\text { DOC, TED e transferências }\end{array}$ & Soma \\
\hline $\begin{array}{l}\text { Valor total de lançamentos de débito de DOC, } \\
\text { TED e transferências }\end{array}$ & Soma \\
\hline Valor total de lançamentos de compras \\
eletrônicas & Soma \\
\hline Valor total de lançamentos de outros & soma \\
\hline pagamentos & soma \\
\hline Valor de aplicações em curto prazo & soma \\
\hline Valor de aplicações em renda variável & \\
\hline Valor de aplicações no exterior & \\
\hline
\end{tabular}


Tabela A.2: Estimativa dos parâmetros do modelo Gama Generalizado.

\begin{tabular}{|c|c|c|c|c|c|c|c|c|}
\hline \multirow{2}{*}{ variável } & \multirow{2}{*}{ intervalo } & \multirow{2}{*}{$\%$} & \multicolumn{3}{|c|}{ Desconsiderando a truncagem } & \multicolumn{3}{|c|}{ Considerando a truncagem } \\
\hline & & & estimativa & erro padräo & p-value & estimativa & erro padrão & p-value \\
\hline Intercepto & & & 7.19 & 0.09 & 0.00 & 7.19 & 0.10 & 0.00 \\
\hline \multirow{3}{*}{ saldo médio credor } & $500-1800$ & $35 \%$ & 0.08 & 0.04 & 0.04 & 0.08 & 0.04 & 0.04 \\
\hline & $1801-3200$ & $10 \%$ & 0.15 & 0.06 & 0.01 & 0.16 & 0.06 & 0.01 \\
\hline & acima de 3200 & $15 \%$ & 0.20 & 0.05 & 0.00 & 0.21 & 0.05 & 0.00 \\
\hline \multirow{4}{*}{$\begin{array}{c}\text { indice de } \\
\text { rentabilidade (IR) do } \\
\text { cliente }\end{array}$} & $5-50$ & $35 \%$ & 0.10 & 0.04 & 0.02 & 0.10 & 0.04 & 0.02 \\
\hline & $51-180$ & $26 \%$ & 0.14 & 0.05 & 0.00 & 0.15 & 0.05 & 0.00 \\
\hline & $181-250$ & $10 \%$ & 0.20 & 0.07 & 0.00 & 0.21 & 0.07 & 0.00 \\
\hline & acima de 250 & $5 \%$ & 0.43 & 0.09 & 0.00 & 0.43 & 0.09 & 0.00 \\
\hline \multirow{2}{*}{$\begin{array}{c}\text { valor do } \\
\text { empréstimo }\end{array}$} & até 2500 & $5 \%$ & -0.24 & 0.07 & 0.00 & -0.26 & 0.07 & 0.00 \\
\hline & $2500-5000$ & $16 \%$ & -0.12 & 0.04 & 0.00 & -0.12 & 0.04 & 0.00 \\
\hline \multirow{2}{*}{$\begin{array}{c}\text { despesa no cartāo } \\
\text { de crédito }\end{array}$} & $1-250$ & $29 \%$ & -0.08 & 0.04 & 0.03 & -0.08 & 0.04 & 0.03 \\
\hline & acima de 2500 & $3 \%$ & 0.21 & 0.11 & 0.05 & 0.18 & 0.11 & 0.09 \\
\hline $\begin{array}{c}\text { proteção máxima } \\
\text { no cartão }\end{array}$ & $\operatorname{sim}$ & $9 \%$ & 0.17 & 0.06 & 0.01 & 0.17 & 0.06 & 0.01 \\
\hline sexo & masculino & $65 \%$ & 0.14 & 0.03 & 0.00 & 0.15 & 0.03 & 0.00 \\
\hline \multirow{2}{*}{ instrução } & superior & $72 \%$ & 0.36 & 0.06 & 0.00 & 0.38 & 0.06 & 0.00 \\
\hline & pós & $18 \%$ & 0.50 & 0.07 & 0.00 & 0.52 & 0.07 & 0.00 \\
\hline estado civil & $\begin{array}{l}\text { casado sep. total de } \\
\text { bens }\end{array}$ & $2 \%$ & 0.27 & 0.13 & 0.04 & 0.27 & 0.14 & 0.05 \\
\hline \multirow{2}{*}{ segmento } & VIP & $0 \%$ & 1.23 & 0.27 & 0.00 & 1.29 & 0.27 & 0.00 \\
\hline & alta renda & $55 \%$ & 0.44 & 0.04 & 0.00 & 0.45 & 0.04 & 0.00 \\
\hline \multirow{2}{*}{ IR investimentos } & $1-60$ & $9 \%$ & 0.10 & 0.06 & 0.08 & 0.10 & 0.06 & 0.09 \\
\hline & acima de 60 & $5 \%$ & 0.53 & 0.08 & 0.00 & 0.54 & 0.08 & 0.00 \\
\hline \multirow{3}{*}{$\begin{array}{l}\text { IR seguros e } \\
\text { previdência } \\
\text { lanc de débito } \\
\text { automático }\end{array}$} & acima de 150 & $12 \%$ & 0.11 & 0.05 & 0.03 & 0.11 & 0.05 & 0.02 \\
\hline & $1-350$ & $10 \%$ & -0.14 & 0.05 & 0.01 & -0.14 & 0.05 & 0.01 \\
\hline & acima de 1500 & $25 \%$ & 0.06 & 0.04 & 0.11 & 0.07 & 0.04 & 0.09 \\
\hline \multirow{2}{*}{$\begin{array}{c}\text { ficha de } \\
\text { compensaçãol }\end{array}$} & $1-350$ & $1 \%$ & -0.28 & 0.14 & 0.04 & -0.32 & 0.14 & 0.02 \\
\hline & $350-700$ & $10 \%$ & -0.13 & 0.05 & 0.01 & -0.15 & 0.05 & 0.00 \\
\hline behavior & $E$ & $2 \%$ & -0.20 & 0.10 & 0.05 & -0.23 & 0.10 & 0.02 \\
\hline tempo de emprego & $8-15$ anos & $3 \%$ & 0.24 & 0.10 & 0.01 & 0.27 & 0.10 & 0.01 \\
\hline lempo de emprego & acima de 15 anos & $4 \%$ & 0.34 & 0.08 & 0.00 & 0.35 & 0.08 & 0.00 \\
\hline doc, ted e & $2400-5600$ & $10 \%$ & 0.12 & 0.05 & 0.02 & 0.13 & 0.06 & 0.02 \\
\hline tranferências & acima de 5600 & $5 \%$ & 0.27 & 0.07 & 0.00 & 0.27 & 0.08 & 0.00 \\
\hline$\%$ rotativo utilizado & $70-85$ & $4 \%$ & -0.16 & 0.08 & 0.04 & -0.16 & 0.08 & 0.04 \\
\hline \% rotaivo uilizado & acima de $85 \%$ & $5 \%$ & -0.23 & 0.07 & 0.00 & -0.24 & 0.07 & 0.00 \\
\hline & agrup 1 & $8 \%$ & 0.14 & 0.07 & 0.03 & 0.15 & 0.07 & 0.03 \\
\hline & agrup 2 & $6 \%$ & -0.21 & 0.07 & 0.00 & -0.21 & 0.07 & 0.00 \\
\hline nrofissāo & agrup 4 & $9 \%$ & 0.20 & 0.06 & 0.00 & 0.20 & 0.06 & 0.00 \\
\hline proissao & agrup 6 & $4 \%$ & 0.15 & 0.08 & 0.07 & 0.16 & 0.09 & 0.07 \\
\hline & agrup 7 & $27 \%$ & 0.11 & 0.05 & 0.02 & 0.11 & 0.05 & 0.02 \\
\hline & agrup 9 & $25 \%$ & 0.62 & 0.05 & 0.00 & 0.63 & 0.05 & 0.00 \\
\hline atde de yeiculos & 2 ou 3 & $51 \%$ & 0.07 & 0.04 & 0.06 & 0.07 & 0.04 & 0.05 \\
\hline que oe vercuios & acima de 3 & $20 \%$ & 0.14 & 0.05 & 0.01 & 0.14 & 0.05 & 0.01 \\
\hline & $100 \mathrm{k}-250 \mathrm{k}$ & $17 \%$ & 0.09 & 0.04 & 0.04 & 0.10 & 0.05 & 0.03 \\
\hline patrimônio & $250 k-320 k$ & $8 \%$ & 0.16 & 0.06 & 0.01 & 0.17 & 0.06 & 0.00 \\
\hline patrimonio & $320 k-680 k$ & $10 \%$ & 0.23 & 0.06 & 0.00 & 0.23 & 0.06 & 0.00 \\
\hline & acima de $680 \mathrm{k}$ & $5 \%$ & 0.28 & 0.08 & 0.00 & 0.30 & 0.08 & 0.00 \\
\hline & $30-35$ & $20 \%$ & 0.37 & 0.07 & 0.00 & 0.39 & 0.07 & 0.00 \\
\hline & $35-40$ & $38 \%$ & 0.43 & 0.07 & 0.00 & 0.45 & 0.07 & 0.00 \\
\hline idade & $40-45$ & $13 \%$ & 0.50 & 0.08 & 0.00 & 0.52 & 0.08 & 0.00 \\
\hline & $45-50$ & $10 \%$ & 0.57 & 0.08 & 0.00 & 0.59 & 0.08 & 0.00 \\
\hline & acima de 50 & $13 \%$ & 0.68 & 0.08 & 0.00 & 0.71 & 0.08 & 0.00 \\
\hline scale & & & 0.69 & 0.02 & 0.00 & 0.68 & 0.02 & 0.00 \\
\hline Shape & & & 0.80 & 0.07 & 0.00 & 1.07 & 0.09 & 0.00 \\
\hline
\end{tabular}


Tabela A.3: Estimativa dos parâmetros do modelo paramétrico final.

\begin{tabular}{|c|c|c|c|c|c|}
\hline \multirow{2}{*}{ variável } & \multirow{2}{*}{ intervalo } & \multirow{2}{*}{$\%$} & \multicolumn{3}{|c|}{ Modelo Weibull com truncagem } \\
\hline & & & estimativa & erro padrão & p-value \\
\hline Intercepto & & & 7.17 & 0.09 & 0.00 \\
\hline \multirow{3}{*}{ saldo médio credor } & $500-1800$ & $35 \%$ & 0.08 & 0.04 & 0.04 \\
\hline & $1801-3200$ & $10 \%$ & 0.16 & 0.06 & 0.01 \\
\hline & acima de 3200 & $15 \%$ & 0.21 & 0.05 & 0.00 \\
\hline \multirow{4}{*}{$\begin{array}{c}\text { índice de } \\
\text { rentabilidade (IR) do } \\
\text { cliente }\end{array}$} & $5-50$ & $35 \%$ & 0.10 & 0.04 & 0.02 \\
\hline & $51-180$ & $26 \%$ & 0.15 & 0.05 & 0.00 \\
\hline & $181-250$ & $10 \%$ & 0.21 & 0.07 & 0.00 \\
\hline & acima de 250 & $5 \%$ & 0.43 & 0.09 & 0.00 \\
\hline \multirow{2}{*}{$\begin{array}{c}\text { valor do } \\
\text { empréstimo }\end{array}$} & até 2500 & $5 \%$ & -0.25 & 0.07 & 0.00 \\
\hline & $2500-5000$ & $16 \%$ & -0.12 & 0.04 & 0.00 \\
\hline \multirow{2}{*}{$\begin{array}{l}\text { despesa no cartão } \\
\text { de crédito }\end{array}$} & $1-250$ & $29 \%$ & -0.08 & 0.04 & 0.03 \\
\hline & acima de 2500 & $3 \%$ & 0.19 & 0.11 & 0.08 \\
\hline $\begin{array}{c}\text { proteção máxima } \\
\text { no cartão }\end{array}$ & $\operatorname{sim}$ & $9 \%$ & 0.17 & 0.06 & 0.01 \\
\hline sexo & masculino & $65 \%$ & 0.15 & 0.04 & 0.00 \\
\hline \multirow{2}{*}{ instrução } & superior & $72 \%$ & 0.38 & 0.06 & 0.00 \\
\hline & pós & $18 \%$ & 0.52 & 0.07 & 0.00 \\
\hline \multirow[t]{3}{*}{ estado civil } & $\begin{array}{c}\text { casado sep. total de } \\
\text { bens }\end{array}$ & $2 \%$ & 0.27 & 0.14 & 0.05 \\
\hline & VIP & $0 \%$ & 1.28 & 0.27 & 0.00 \\
\hline & alta renda & $55 \%$ & 0.45 & 0.04 & 0.00 \\
\hline \multirow{2}{*}{ IR investimentos } & $1-60$ & $9 \%$ & 0.10 & 0.06 & 0.09 \\
\hline & acima de 60 & $5 \%$ & 0.54 & 0.08 & 0.00 \\
\hline \multirow{3}{*}{$\begin{array}{l}\text { IR seguros e } \\
\text { previdência } \\
\text { lanc de débito } \\
\text { automático }\end{array}$} & acima de 150 & $12 \%$ & 0.11 & 0.05 & 0.03 \\
\hline & $1-350$ & $10 \%$ & -0.14 & 0.05 & 0.01 \\
\hline & acima de 1500 & $25 \%$ & 0.06 & 0.04 & 0.10 \\
\hline \multirow{2}{*}{$\begin{array}{c}\text { ficha de } \\
\text { compensação/ }\end{array}$} & $1-350$ & $1 \%$ & -0.31 & 0.14 & 0.03 \\
\hline & $350-700$ & $10 \%$ & -0.15 & 0.05 & 0.01 \\
\hline behavior & $E$ & $2 \%$ & -0.22 & 0.10 & 0.02 \\
\hline \multirow{2}{*}{ tempo de emprego } & $8-15$ anos & $3 \%$ & 0.26 & 0.10 & 0.01 \\
\hline & acima de 15 anos & $4 \%$ & 0.35 & 0.08 & 0.00 \\
\hline \multirow{2}{*}{$\begin{array}{c}\text { doc, ted e } \\
\text { tranferências }\end{array}$} & $2400-5600$ & $10 \%$ & 0.13 & 0.06 & 0.02 \\
\hline & acima de 5600 & $5 \%$ & 0.27 & 0.08 & 0.00 \\
\hline \multirow{2}{*}{$\%$ rotativo utilizado } & $70-85$ & $4 \%$ & -0.16 & 0.08 & 0.04 \\
\hline & acima de $85 \%$ & $5 \%$ & -0.24 & 0.07 & 0.00 \\
\hline \multirow{6}{*}{ profissão } & agrup 1 & $8 \%$ & 0.15 & 0.07 & 0.03 \\
\hline & agrup 2 & $6 \%$ & -0.21 & 0.07 & 0.00 \\
\hline & agrup 4 & $9 \%$ & 0.20 & 0.06 & 0.00 \\
\hline & agrup 6 & $4 \%$ & 0.16 & 0.09 & 0.07 \\
\hline & agrup 7 & $27 \%$ & 0.11 & 0.05 & 0.02 \\
\hline & agrup 9 & $25 \%$ & 0.63 & 0.05 & 0.00 \\
\hline \multirow{2}{*}{ qtde de veículos } & 2 ou 3 & $51 \%$ & 0.07 & 0.04 & 0.05 \\
\hline & acima de 3 & $20 \%$ & 0.14 & 0.05 & 0.01 \\
\hline & $100 k-250 k$ & $17 \%$ & 0.10 & 0.05 & 0.03 \\
\hline patrimônio & $250 k-320 k$ & $8 \%$ & 0.17 & 0.06 & 0.00 \\
\hline patminomo & $320 k-680 k$ & $10 \%$ & 0.23 & 0.06 & 0.00 \\
\hline & acima de $680 \mathrm{k}$ & $5 \%$ & 0.29 & 0.08 & 0.00 \\
\hline & $30-35$ & $20 \%$ & 0.39 & 0.07 & 0.00 \\
\hline & $35-40$ & $38 \%$ & 0.45 & 0.07 & 0.00 \\
\hline idade & $40-45$ & $13 \%$ & 0.52 & 0.08 & 0.00 \\
\hline & $45-50$ & $10 \%$ & 0.59 & 0.08 & 0.00 \\
\hline & acima de 50 & $13 \%$ & 0.71 & 0.08 & 0.00 \\
\hline scale & & & 0.69 & 0.01 & 0.00 \\
\hline
\end{tabular}


Tabela A.4: Estimativa dos parâmetros do modelo semi-paramétrico final.

\begin{tabular}{|c|c|c|c|c|c|}
\hline \multirow{2}{*}{ variável } & \multirow{2}{*}{ intervalo } & \multirow{2}{*}{$\%$} & \multicolumn{3}{|c|}{ Modelo de Cox } \\
\hline & & & estimativa & erro padrão & p-value \\
\hline \multirow{3}{*}{ saldo médio credor } & $500-1800$ & $35 \%$ & -0.03 & 0.02 & 0.10 \\
\hline & $1801-3200$ & $10 \%$ & -0.19 & 0.06 & 0.00 \\
\hline & acima de 3200 & $15 \%$ & -0.22 & 0.04 & 0.00 \\
\hline \multirow{4}{*}{$\begin{array}{c}\text { índice de } \\
\text { rentabilidade (IR) do } \\
\text { cliente }\end{array}$} & $5-50$ & $35 \%$ & -0.07 & 0.04 & 0.08 \\
\hline & $51-180$ & $26 \%$ & -0.18 & 0.06 & 0.00 \\
\hline & $181-250$ & $10 \%$ & -0.29 & 0.08 & 0.00 \\
\hline & acima de 250 & $5 \%$ & -0.62 & 0.06 & 0.00 \\
\hline \multirow{2}{*}{$\begin{array}{c}\text { valor do } \\
\text { empréstimo }\end{array}$} & até 2500 & $5 \%$ & 0.42 & 0.09 & 0.00 \\
\hline & $2500-5000$ & $16 \%$ & 0.25 & 0.03 & 0.00 \\
\hline \multirow{2}{*}{$\begin{array}{l}\text { despesa no cartão } \\
\text { de crédito }\end{array}$} & $1-250$ & $29 \%$ & 0.18 & 0.04 & 0.00 \\
\hline & acima de 2500 & $3 \%$ & -0.22 & 0.12 & 0.06 \\
\hline $\begin{array}{c}\begin{array}{c}\text { proteção máxima } \\
\text { no cartão }\end{array} \\
\end{array}$ & $\operatorname{sim}$ & $9 \%$ & -0.23 & 0.05 & 0.00 \\
\hline sexo & masculino & $65 \%$ & -0.16 & 0.03 & 0.00 \\
\hline \multirow{2}{*}{ instrução } & superior & $72 \%$ & -0.50 & 0.07 & 0.00 \\
\hline & pós & $18 \%$ & -0.69 & 0.05 & 0.00 \\
\hline estado civil & $\begin{array}{l}\text { casado sep. total de } \\
\text { bens }\end{array}$ & $2 \%$ & -0.39 & 0.15 & 0.01 \\
\hline \multirow{2}{*}{ segmento } & VIP & $0 \%$ & -1.85 & 0.31 & 0.00 \\
\hline & alta renda & $55 \%$ & -0.62 & 0.02 & 0.00 \\
\hline \multirow{2}{*}{ IR investimentos } & $1-60$ & $9 \%$ & -0.13 & 0.05 & 0.02 \\
\hline & acima de 60 & $5 \%$ & -0.73 & 0.10 & 0.00 \\
\hline $\begin{array}{l}\text { IR seguros e } \\
\text { previdência }\end{array}$ & acima de 150 & $12 \%$ & -0.12 & 0.05 & 0.01 \\
\hline \multirow{2}{*}{$\begin{array}{l}\text { lanc de débito } \\
\text { automático }\end{array}$} & $1-350$ & $10 \%$ & 0.25 & 0.05 & 0.00 \\
\hline & acima de 1500 & $25 \%$ & -0.04 & 0.02 & 0.08 \\
\hline \multirow{2}{*}{$\begin{array}{c}\text { ficha de } \\
\text { compensação/ }\end{array}$} & $1-350$ & $1 \%$ & 0.60 & 0.11 & 0.00 \\
\hline & $350-700$ & $10 \%$ & 0.22 & 0.04 & 0.00 \\
\hline behavior & $\mathrm{E}$ & $2 \%$ & 0.36 & 0.11 & 0.00 \\
\hline \multirow{2}{*}{ tempo de emprego } & $8-15$ anos & $3 \%$ & -0.32 & 0.11 & 0.00 \\
\hline & acima de 15 anos & $4 \%$ & -0.49 & 0.07 & 0.00 \\
\hline \multirow{2}{*}{$\begin{array}{c}\text { doc, ted e } \\
\text { tranferências }\end{array}$} & $2400-5600$ & $10 \%$ & -0.16 & 0.06 & 0.01 \\
\hline & acima de 5600 & $5 \%$ & -0.37 & 0.07 & 0.00 \\
\hline \multirow{2}{*}{$\%$ rotativo utilizado } & $70-85$ & $4 \%$ & 0.29 & 0.08 & 0.00 \\
\hline & acima de $85 \%$ & $5 \%$ & 0.37 & 0.07 & 0.00 \\
\hline \multirow{6}{*}{ profissão } & agrup 1 & $8 \%$ & -0.17 & 0.06 & 0.00 \\
\hline & agrup 2 & $6 \%$ & 0.34 & 0.06 & 0.00 \\
\hline & agrup 4 & $9 \%$ & -0.27 & 0.05 & 0.00 \\
\hline & agrup 6 & $4 \%$ & -0.15 & 0.09 & 0.08 \\
\hline & agrup 7 & $27 \%$ & -0.12 & 0.04 & 0.01 \\
\hline & agrup 9 & $25 \%$ & -0.90 & 0.06 & 0.00 \\
\hline atde 0 & 2 ou 3 & $51 \%$ & -0.08 & 0.04 & 0.02 \\
\hline & acima de 3 & $20 \%$ & -0.23 & 0.05 & 0.00 \\
\hline & $100 \mathrm{k}-250 \mathrm{k}$ & $17 \%$ & -0.08 & 0.04 & 0.08 \\
\hline patrimônio & $250 k-320 k$ & $8 \%$ & -0.19 & 0.05 & 0.00 \\
\hline & $320 k-680 k$ & $10 \%$ & -0.36 & 0.05 & 0.00 \\
\hline & acima de $680 \mathrm{k}$ & $5 \%$ & -0.39 & 0.06 & 0.00 \\
\hline & $30-35$ & $20 \%$ & -0.42 & 0.07 & 0.00 \\
\hline & $35-40$ & $38 \%$ & -0.54 & 0.08 & 0.00 \\
\hline idade & $40-45$ & $13 \%$ & -0.64 & 0.10 & 0.00 \\
\hline & $45-50$ & $10 \%$ & -0.77 & 0.06 & 0.00 \\
\hline & acima de 50 & $13 \%$ & -0.93 & 0.08 & 0.00 \\
\hline
\end{tabular}


Tabela A.5: Comparação da renda predita com as renda confiáveis.

\begin{tabular}{|c|c|c|c|c|}
\hline variável & intervalo & $\begin{array}{l}\text { Renda média para } \\
\text { as falhas }\end{array}$ & $\begin{array}{l}\text { média das medianas } \\
\text { estimadas Weibull }\end{array}$ & $\begin{array}{c}\text { média das medianas } \\
\text { estimadas Cox }\end{array}$ \\
\hline \multirow{3}{*}{ saldo médio credor } & $500-1800$ & $\mathrm{R} \$ 6,160$ & $\mathrm{R} \$ 6,812$ & $\mathrm{R} \$ 6,826$ \\
\hline & $1801-3200$ & $\mathrm{R} \$ 8,381$ & $\mathrm{R} \$ 8,992$ & $\mathrm{R} \$ 9,123$ \\
\hline & acima de 3200 & $\mathrm{R} \$ 9,700$ & $\mathrm{R} \$ 11,230$ & $R \$ 11,032$ \\
\hline \multirow{4}{*}{$\begin{array}{c}\text { indice de } \\
\text { rentabilidade (IR) do } \\
\text { cliente }\end{array}$} & $5-50$ & $\mathrm{R} \$ 6,009$ & $\mathrm{R} \$ 6,340$ & $\mathrm{R} \$ 6,376$ \\
\hline & $51-180$ & $\mathrm{R} \$ 7,515$ & $\mathrm{R} \$ 7,742$ & $\mathrm{R} \$ 7,840$ \\
\hline & $181-250$ & $\mathrm{R} \$ 7,154$ & $\mathrm{R} \$ 9,077$ & $\mathrm{R} \$ 9,185$ \\
\hline & acima de 250 & $\mathrm{R} \$ 11,174$ & $R \$ 13,944$ & $\mathrm{R} \$ 13,871$ \\
\hline \multirow{2}{*}{$\begin{array}{l}\text { valor do } \\
\text { empréstimo }\end{array}$} & até 2500 & $R \$ 2,943$ & $\mathrm{R} \$ 2,931$ & $R \$ 2,983$ \\
\hline & $2500-5000$ & $\mathrm{R} \$ 6,944$ & $\mathrm{R} \$ 7,206$ & $\mathrm{R} \$ 7,203$ \\
\hline \multirow{2}{*}{$\begin{array}{l}\text { despesa no cartão } \\
\text { de crédito }\end{array}$} & $1-250$ & $R \$ 6,369$ & $\mathrm{R} \$ 6,847$ & $\mathrm{R} \$ 6,745$ \\
\hline & acima de 2500 & $\mathrm{R} \$ 13,998$ & $\mathrm{R} \$ 14,567$ & $\mathrm{R} \$ 14,051$ \\
\hline $\begin{array}{c}\text { proteção máxima } \\
\text { no cartăo }\end{array}$ & $\operatorname{sim}$ & $\mathrm{R} \$ 8,405$ & $R \$ 10,435$ & $\mathrm{R} \$ 10,257$ \\
\hline sexo & masculino & $\mathrm{R} \$ 7,532$ & $\mathrm{R} \$ 8,271$ & $\mathrm{R} \$ 8,325$ \\
\hline \multirow{2}{*}{ instrução } & superior & $R \$ 6,423$ & $\mathrm{R} \$ 7,176$ & $\mathrm{R} \$ 7,296$ \\
\hline & pós & $\mathrm{R} \$ 10,263$ & $\mathrm{R} \$ 10,360$ & $\mathrm{R} \$ 10,511$ \\
\hline estado civil & $\begin{array}{l}\text { casado sep. total de } \\
\text { bens }\end{array}$ & $\mathrm{R} \$ 7,244$ & $\mathrm{R} \$ 10,138$ & $R \$ 10,295$ \\
\hline \multirow{2}{*}{ segmento } & VIP & $\mathrm{R} \$ 10,138$ & $\mathrm{R} \$ 14,837$ & $\mathrm{R} \$ 15,892$ \\
\hline & alta renda & $\mathrm{R} \$ 9,331$ & $\mathrm{R} \$ 10,262$ & $\mathrm{R} \$ 10,368$ \\
\hline IR investimentos & $\begin{array}{c}1-60 \\
\text { acima de } 60\end{array}$ & $\begin{array}{l}\mathrm{R} \$ 9,262 \\
\mathrm{R} \$ 14,214\end{array}$ & $\begin{array}{l}\mathrm{R} \$ 9,045 \\
\mathrm{R} \$ 17,103\end{array}$ & $\begin{array}{l}\mathrm{R} \$ 9,085 \\
\mathrm{R} \$ 16,165\end{array}$ \\
\hline $\begin{array}{l}\text { IR seguros } \mathrm{e} \\
\text { previdência }\end{array}$ & acima de 150 & $R \$ 7,955$ & $\mathrm{R} \$ 9,171$ & $\mathrm{R} \$ 8,856$ \\
\hline \multirow{2}{*}{$\begin{array}{l}\text { lanc de débito } \\
\text { automático }\end{array}$} & $1-350$ & $\mathrm{R} \$ 5,338$ & $\mathrm{R} \$ 5,274$ & $\mathrm{R} \$ 5,265$ \\
\hline & acima de 1500 & $\mathrm{R} \$ 8,634$ & $\mathrm{R} \$ 9,680$ & $R \$ 9,459$ \\
\hline \multirow{2}{*}{$\begin{array}{c}\text { ficha de } \\
\text { compensaçãol }\end{array}$} & $1-350$ & $R \$ 4,875$ & $\mathrm{R} \$ 5,684$ & $\mathrm{R} \$ 5,319$ \\
\hline & $350-700$ & $\mathrm{R} \$ 8,634$ & $\mathrm{R} \$ 9,680$ & $\mathrm{R} \$ 6,326$ \\
\hline behavior & $\mathrm{E}$ & $\mathrm{R} \$ 9,292$ & $\mathrm{R} \$ 8,418$ & $\mathrm{R} \$ 8,085$ \\
\hline \multirow{2}{*}{ tempo de emprego } & $8-15$ anos & $\mathrm{R} \$ 7,484$ & $\mathrm{R} \$ 10,419$ & $\mathrm{R} \$ 10,154$ \\
\hline & acima de 15 anos & $\mathrm{R} \$ 15,781$ & $R \$ 13,787$ & $R \$ 13,696$ \\
\hline \multirow{2}{*}{$\begin{array}{c}\text { doc, ted e } \\
\text { tranferências }\end{array}$} & $2400-5600$ & $\mathrm{R} \$ 7,275$ & $\mathrm{R} \$ 9,172$ & $\mathrm{R} \$ 8,944$ \\
\hline & acima de 5600 & $\mathrm{R} \$ 9,985$ & $\mathrm{R} \$ 12,416$ & $R \$ 12,108$ \\
\hline \multirow{2}{*}{$\%$ rotativo utilizado } & $70-85$ & $R \$ 4,883$ & $\mathrm{R} \$ 4,635$ & $\mathrm{R} \$ 4,634$ \\
\hline & acima de $85 \%$ & $\mathrm{R} \$ 4,755$ & $\mathrm{R} \$ 4,768$ & $\mathrm{R} \$ 4,823$ \\
\hline \multirow{6}{*}{ profissāo } & agrup 1 & $\mathrm{R} \$ 4,119$ & $R \$ 4,763$ & $\mathrm{R} \$ 4,855$ \\
\hline & agrup 2 & $\mathrm{R} \$ 3,514$ & $\mathrm{R} \$ 3,870$ & $\mathrm{R} \$ 3,917$ \\
\hline & agrup 4 & $R \$ 5,962$ & $\mathrm{R} \$ 5,908$ & $\mathrm{R} \$ 6,094$ \\
\hline & agrup 6 & $R \$ 5,096$ & $\mathrm{R} \$ 5,602$ & $R \$ 5,567$ \\
\hline & agrup 7 & $\mathrm{R} \$ 6,344$ & $\mathrm{R} \$ 6,589$ & $\mathrm{R} \$ 6,591$ \\
\hline & agrup 9 & $\mathrm{R} \$ 11,619$ & $R \$ 12,941$ & $\mathrm{R} \$ 13,179$ \\
\hline \multirow{2}{*}{ qtde de veículos } & 2 ou 3 & $\mathrm{R} \$ 6,578$ & $R \$ 7,013$ & $\mathrm{R} \$ 7,033$ \\
\hline & acima de 3 & $\mathrm{R} \$ 9,253$ & $R \$ 10,584$ & $R \$ 10,861$ \\
\hline \multirow{4}{*}{ patrimônio } & $100 \mathrm{k}-250 \mathrm{k}$ & $\mathrm{R} \$ 7,888$ & $\mathrm{R} \$ 8,089$ & $\mathrm{R} \$ 8,016$ \\
\hline & $250 k-320 k$ & $R \$ 9,088$ & $\mathrm{R} \$ 9,764$ & $\mathrm{R} \$ 9,615$ \\
\hline & $320 k-680 k$ & $R \$ 9,827$ & $R \$ 11,366$ & $\mathrm{R} \$ 11,761$ \\
\hline & acima de $680 \mathrm{k}$ & $\mathrm{R} \$ 9,127$ & $R \$ 13,325$ & $R \$ 13,300$ \\
\hline \multirow{5}{*}{ idade } & $30-35$ & $R \$ 5,584$ & $\mathrm{R} \$ 5,780$ & $R \$ 5,813$ \\
\hline & $35-40$ & $R \$ 6,753$ & $R \$ 6,860$ & $\mathrm{R} \$ 7,010$ \\
\hline & $40-45$ & $\mathrm{R} \$ 7,190$ & $\mathrm{R} \$ 8,561$ & $\mathrm{R} \$ 8,711$ \\
\hline & $45-50$ & $\mathrm{R} \$ 8,132$ & $\mathrm{R} \$ 9,904$ & $R \$ 10,129$ \\
\hline & acima de 50 & $\mathrm{R} \$ 8,946$ & $\mathrm{R} \$ 10,191$ & $R \$ 10,242$ \\
\hline
\end{tabular}


Tabela A.6: Agrupamento de profissão utilizado.

\begin{tabular}{cl}
\hline Agrupamento & \multicolumn{1}{c}{ Profissão } \\
\hline \hline 1 & Agrônomo, Economista, Administrador \\
2 & Professor 1o e 2o grau, Tec. Mecânica, Tec. Eletrônica \\
3 & Arquiteto, Biólogo, Jornalista, Decorador \\
4 & Prof. Superior, Publicitário, Outros médicos \\
5 & Enfermeiro, Físico, Bancário \\
6 & Empresário artist., Engenheiro, Advogado \\
7 & Atleta, Fisio, Fono, Desenhista Ind \\
8 & Contador, Gerente, Músico \\
9 & Dentista, Odontólogo, Médico \\
\hline
\end{tabular}




\subsection{Apêndice B - Macros SAS}

Nesse Apêndice, estão dispostos os programas SAS utilizados no ajuste dos modelos. Ressalta-se que possivelmente os programas não estão construidos da melhor forma, de modo a aperfeiçoar o tempo de processamento.

A macro abaixo define a forma da função densidade de probabilidades e a função de sobrevivência para construção da função de verossimilhança para os modelos de Weibull e Gama Generalizado.

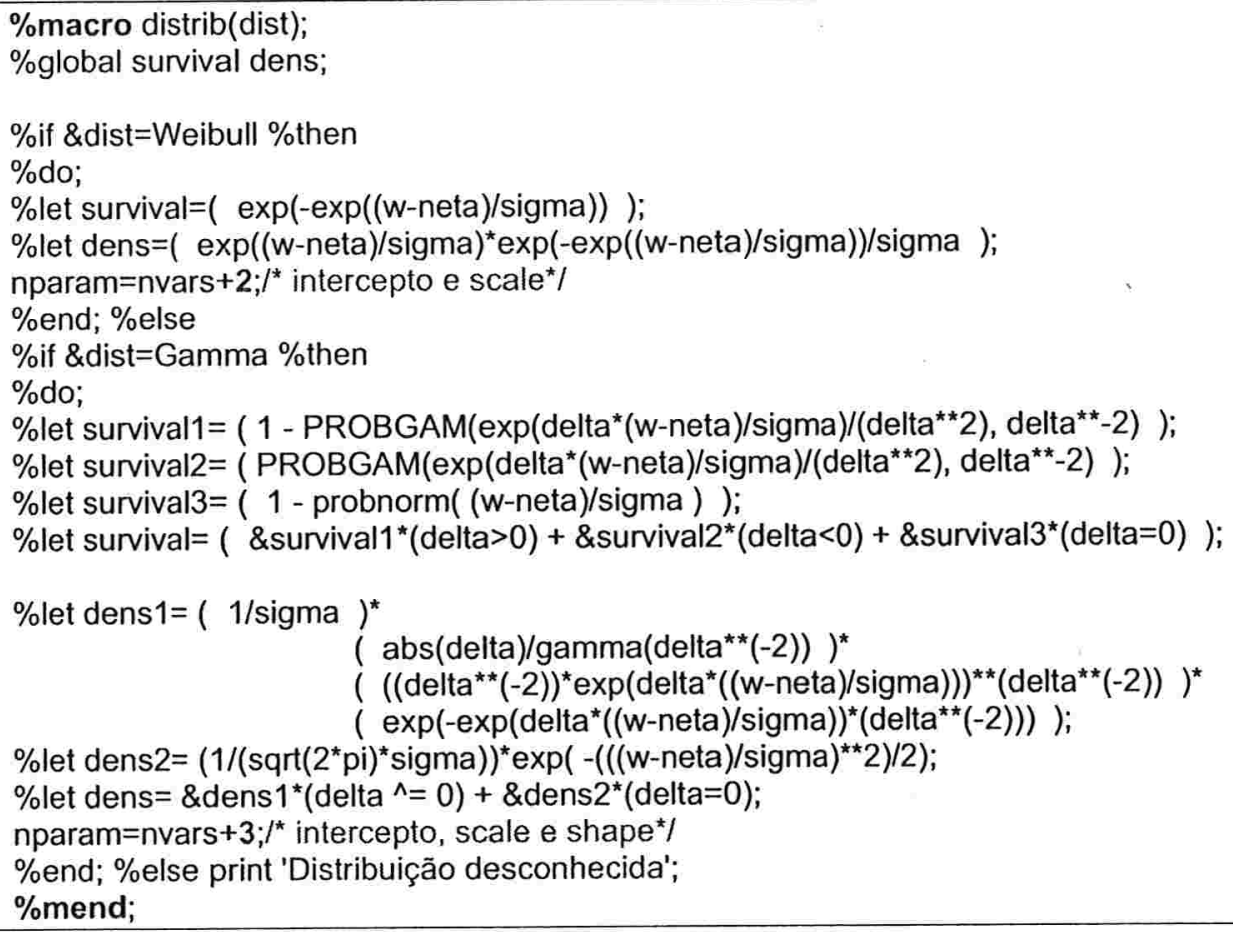

A macro paramétrico ajusta o modelo paramétrico para censura intervalar permitindo a incorporação de truncagem na construção da verossimilhança. Foi desenvolvida comportando as distribuições Weibull e Gama generalizada. O limite inferior e o superior da variável resposta devem se chamar respectivamente left e right. A censura à direita deve caracterizar-se por ter o 
valor de right faltante e, similarmente, o valor de left faltante indica censura à esquerda.

Os parâmetros de entrada na macro são:

- Base: A base que contém os dados;

- Vars: o nome das variáveis explicativas;

- Ltrunc: valor da truncagem à esquerda;

- Dist: distribuição a ser utilizada (Weibull ou Gamma);

- Q_pred: Valor do quantil da distribuição de sobrevivência utilizado para a previsão;

- Saida: nome da tabela de saída.

A macro devolve como saída:

- O logaritmo da verossimilhança ajustada;

- A estimativa dos parâmetros juntamente com a estimativa do erro padrão;

- Uma tabela contendo: A variável resposta, a estimativa da função de sobrevivência no limite superior do intervalo (se existir) ou no limite inferior, a estimativa do erro padrão e o valor do quantil predito.

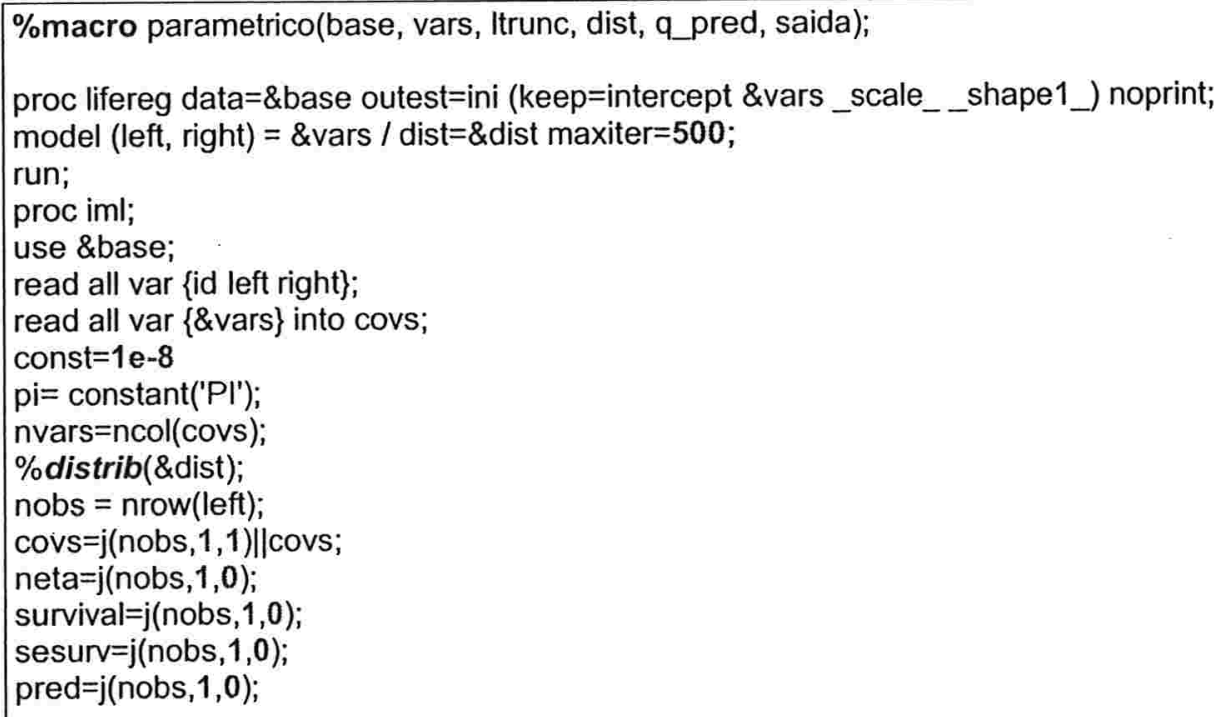




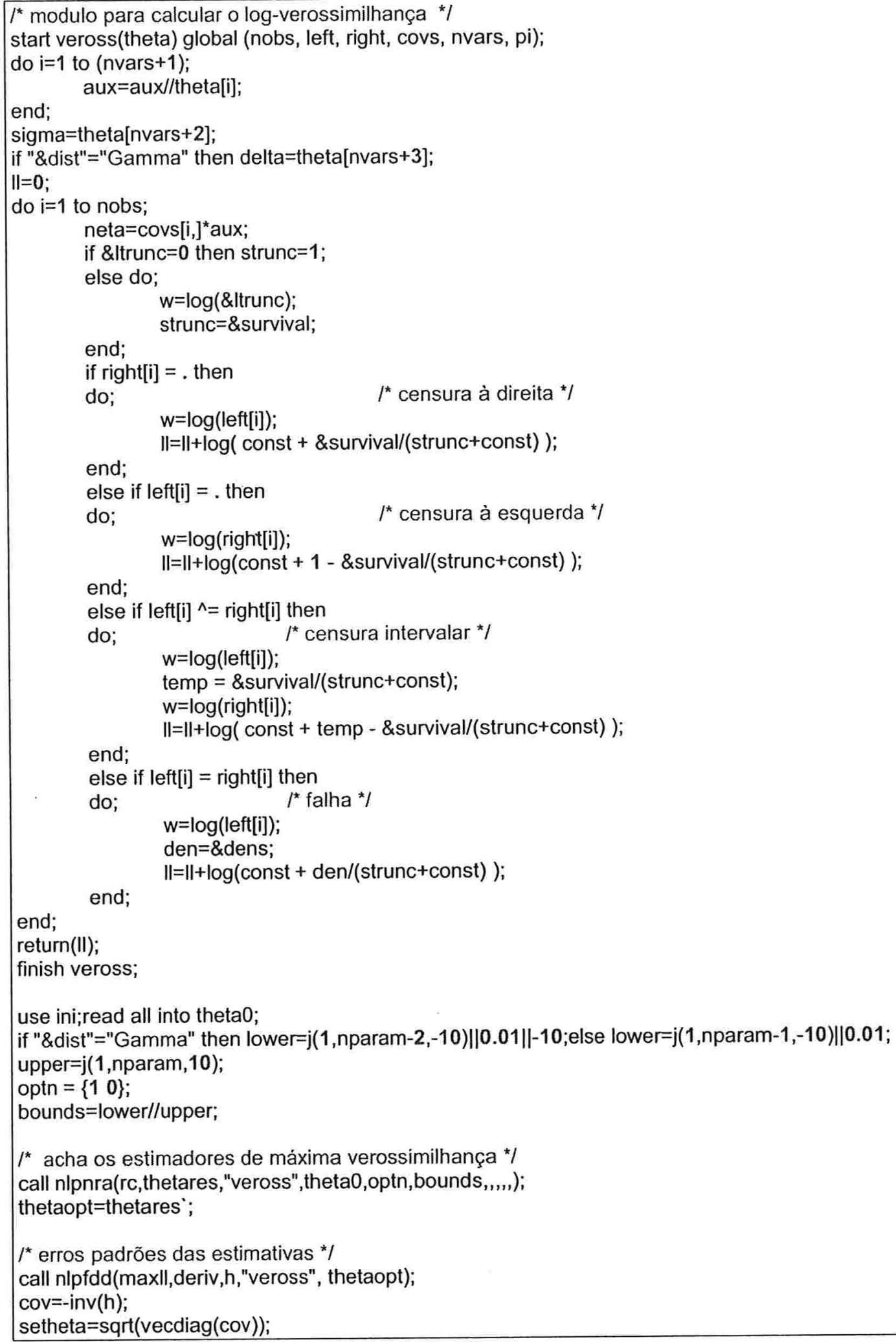




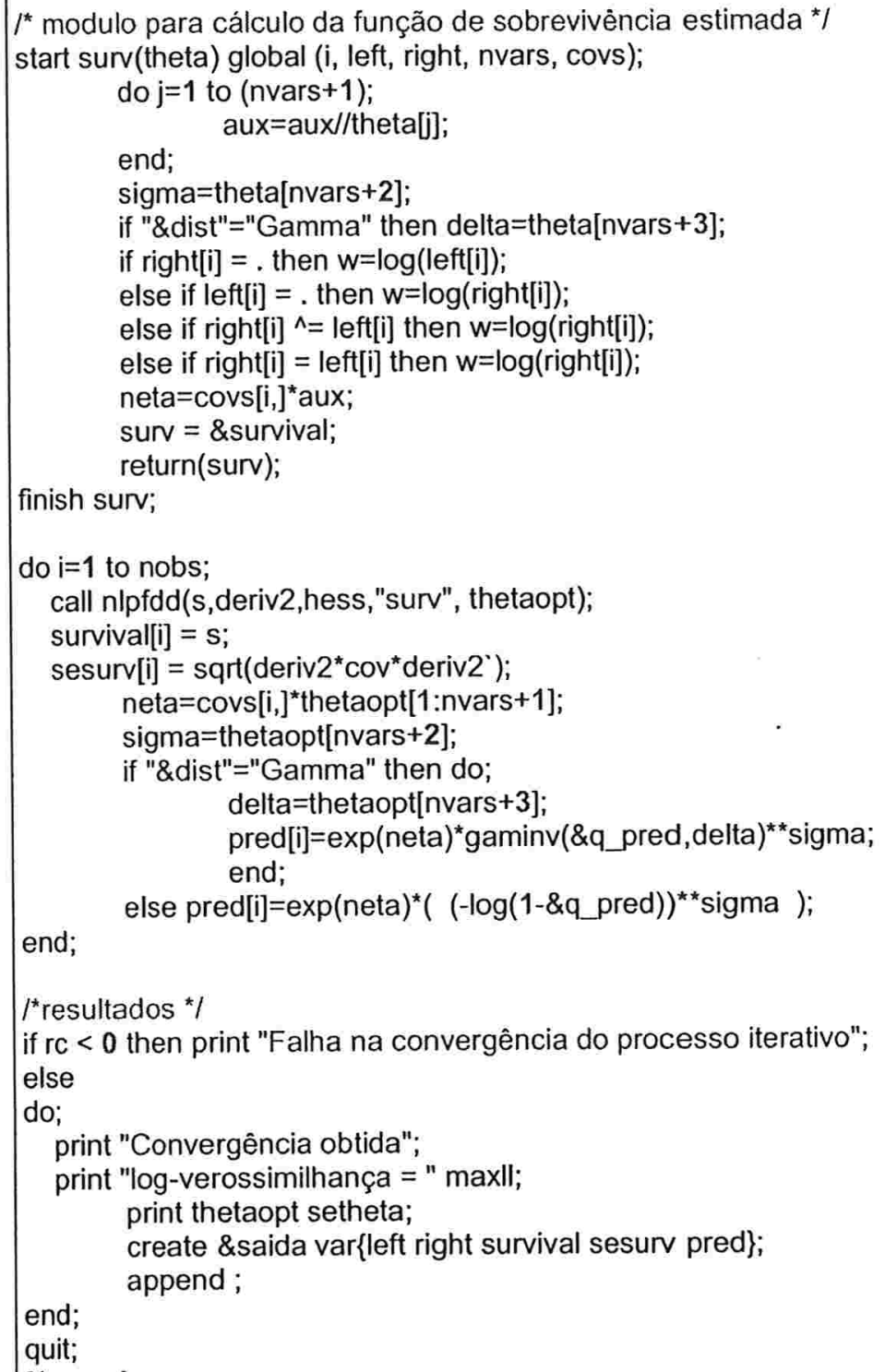

A macro semiparamétrico ajusta o modelo de riscos proporcionais de Cox pelo algoritmo ICM para censura intervalar. A estrutura da base aceita é a mesma explicada anteriormente para a macro paramétrico.

Os parâmetros de entrada na macro são:

- Base: A base que contém os dados; 
- Vars: o nome das variáveis explicativas;

- Ltrunc: valor da truncagem à esquerda;

- Q_pred: Valor do quantil da distribuição de sobrevivência utilizado para a previsão;

- Saída: nome da tabela de saída;

- Eps: diferença mínima nas verossimilhanças no processo iterativo;

- Itmax: número máximo de iterações.

A macro devolve como saída:

- A verossimilhança ajustada;

- O número de iterações necessário;

- O motivo de término do algoritmo

(abbruch =1: Algoritmo convergiu;

abbruch =2: Não é possível acréscimo na verossimilhança;

abbruch =3:Algoritmo não convergiu até o número máximo de iterações

abbruch $=4$ : Condições do algoritmo violadas no passo)

- A estimativa dos parâmetros;

- A estimativa da função de risco acumulada da basal;

- Uma tabela contendo: A variável resposta, a estimativa da função de sobrevivência no limite superior do intervalo e no limite inferior e o valor do quantil predito.

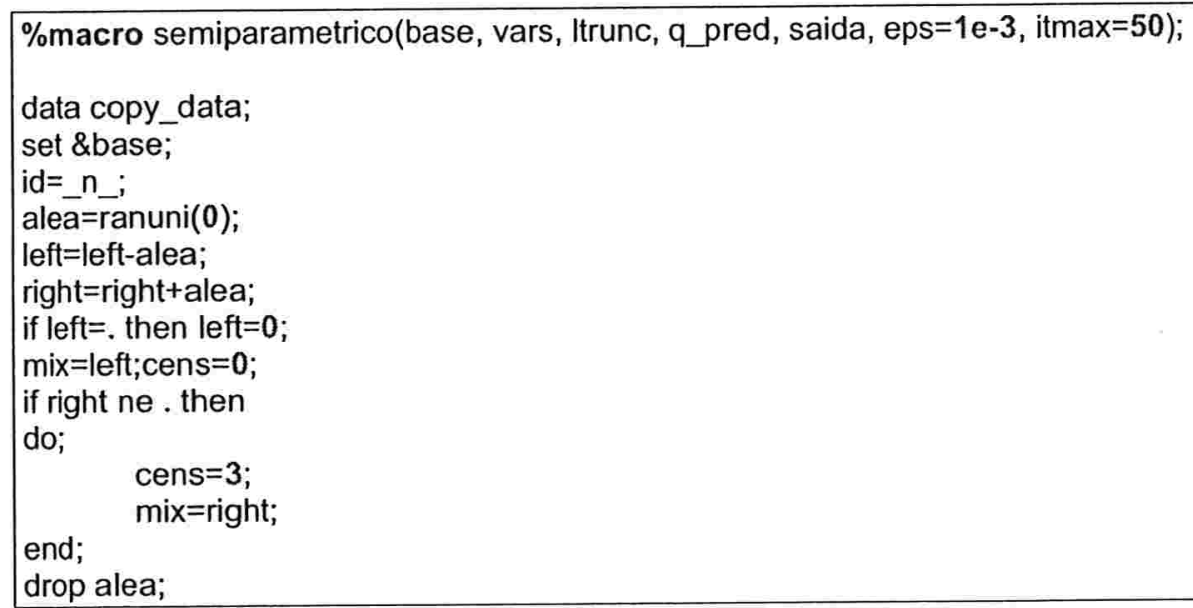




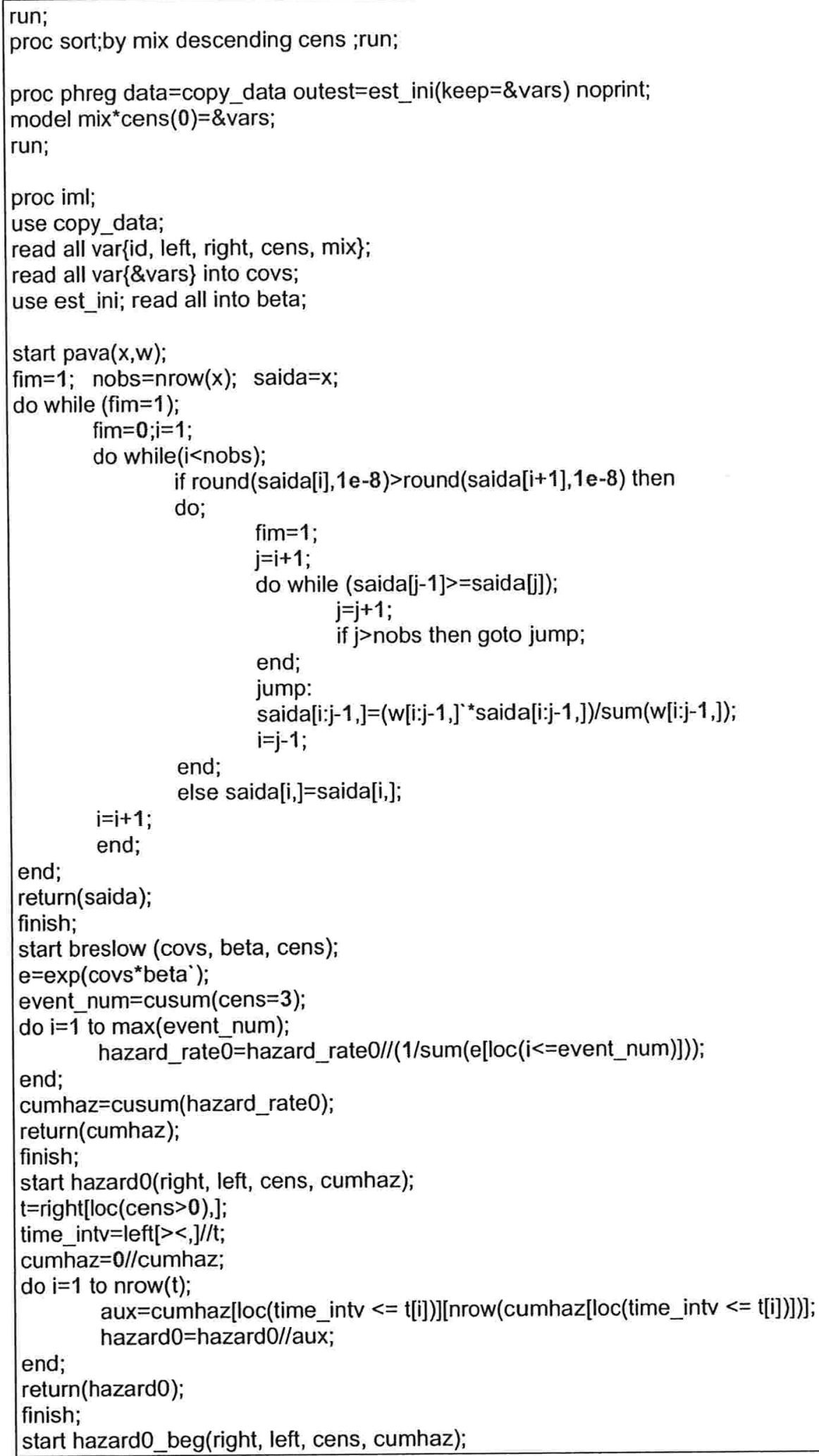




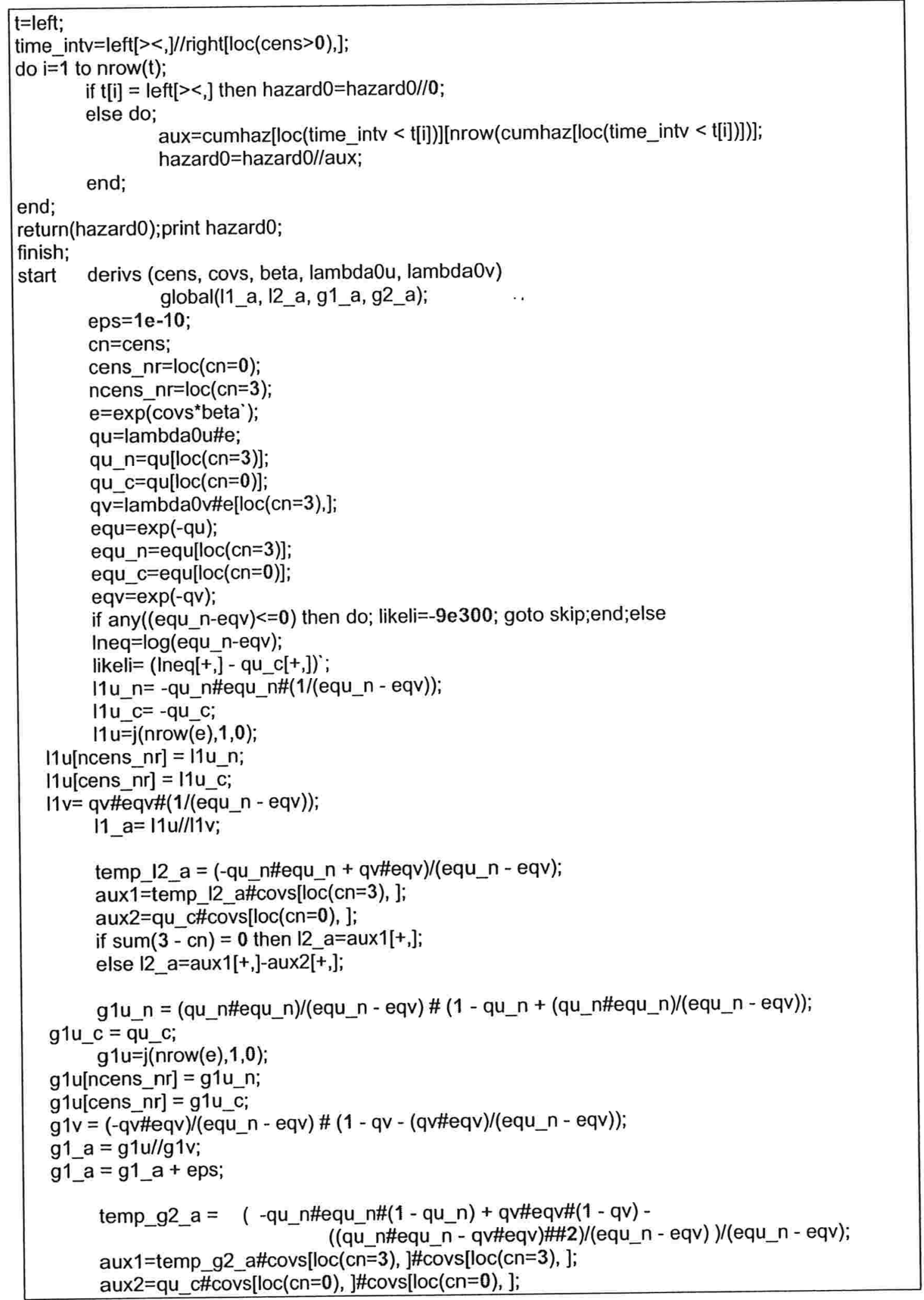




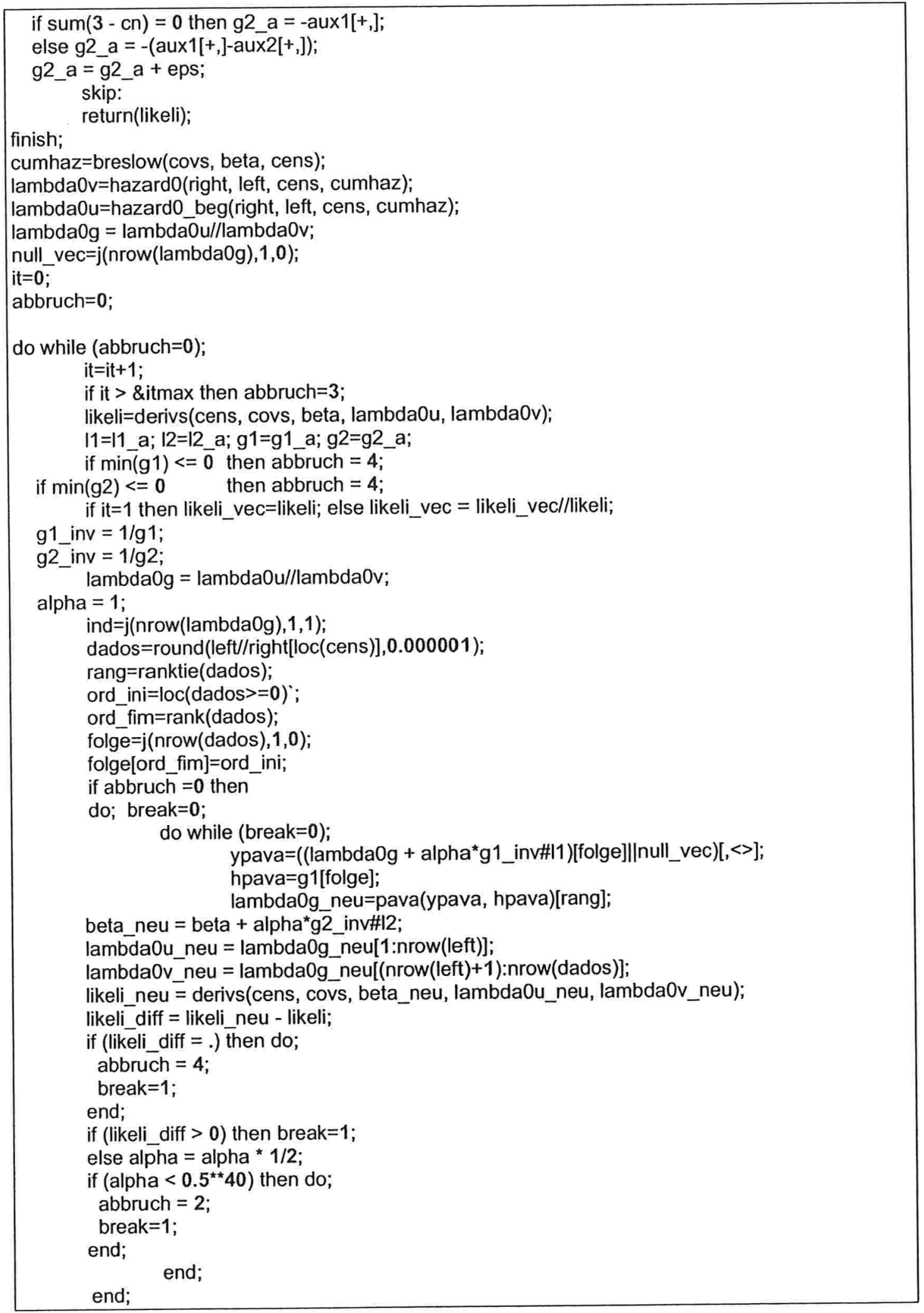




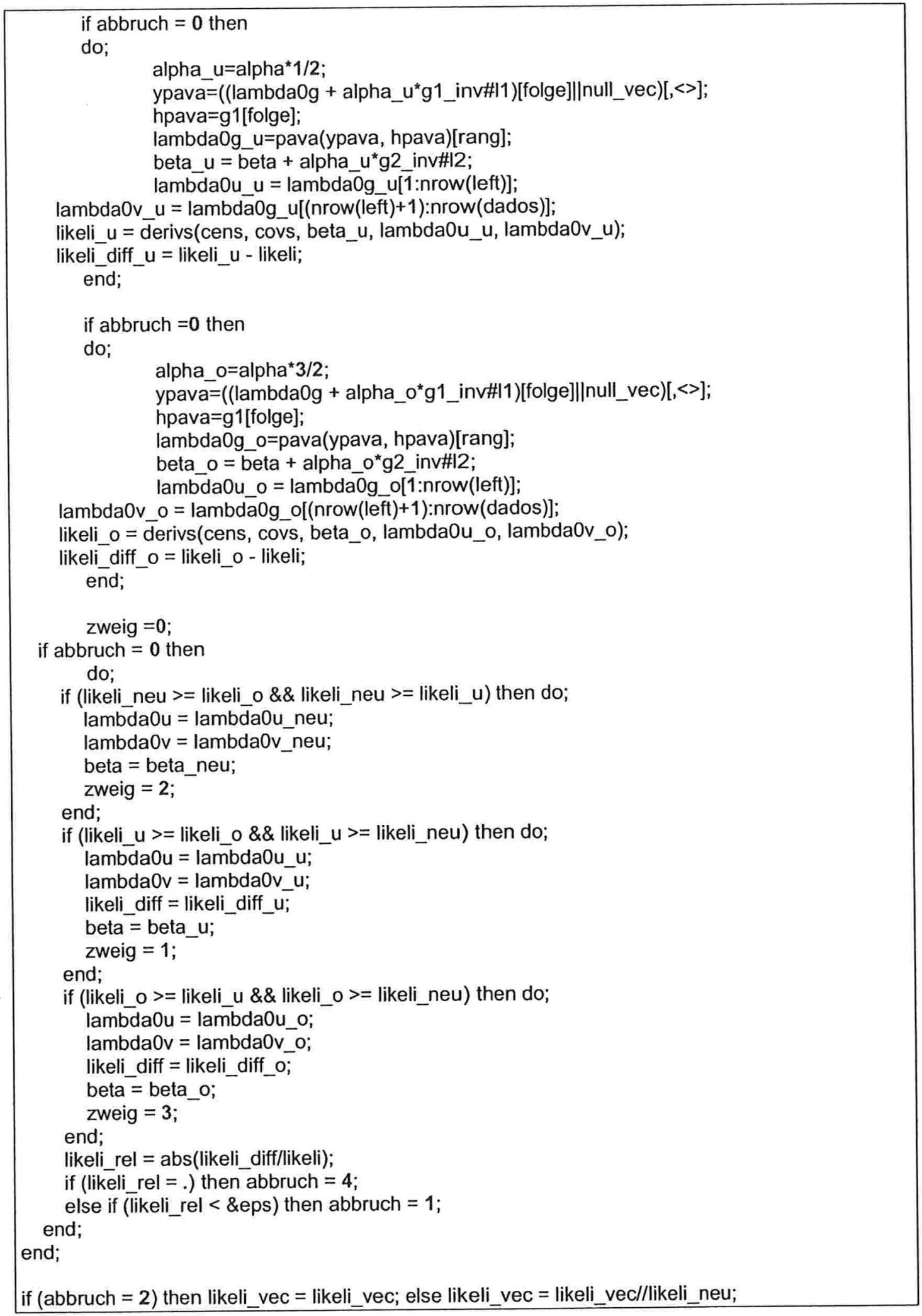




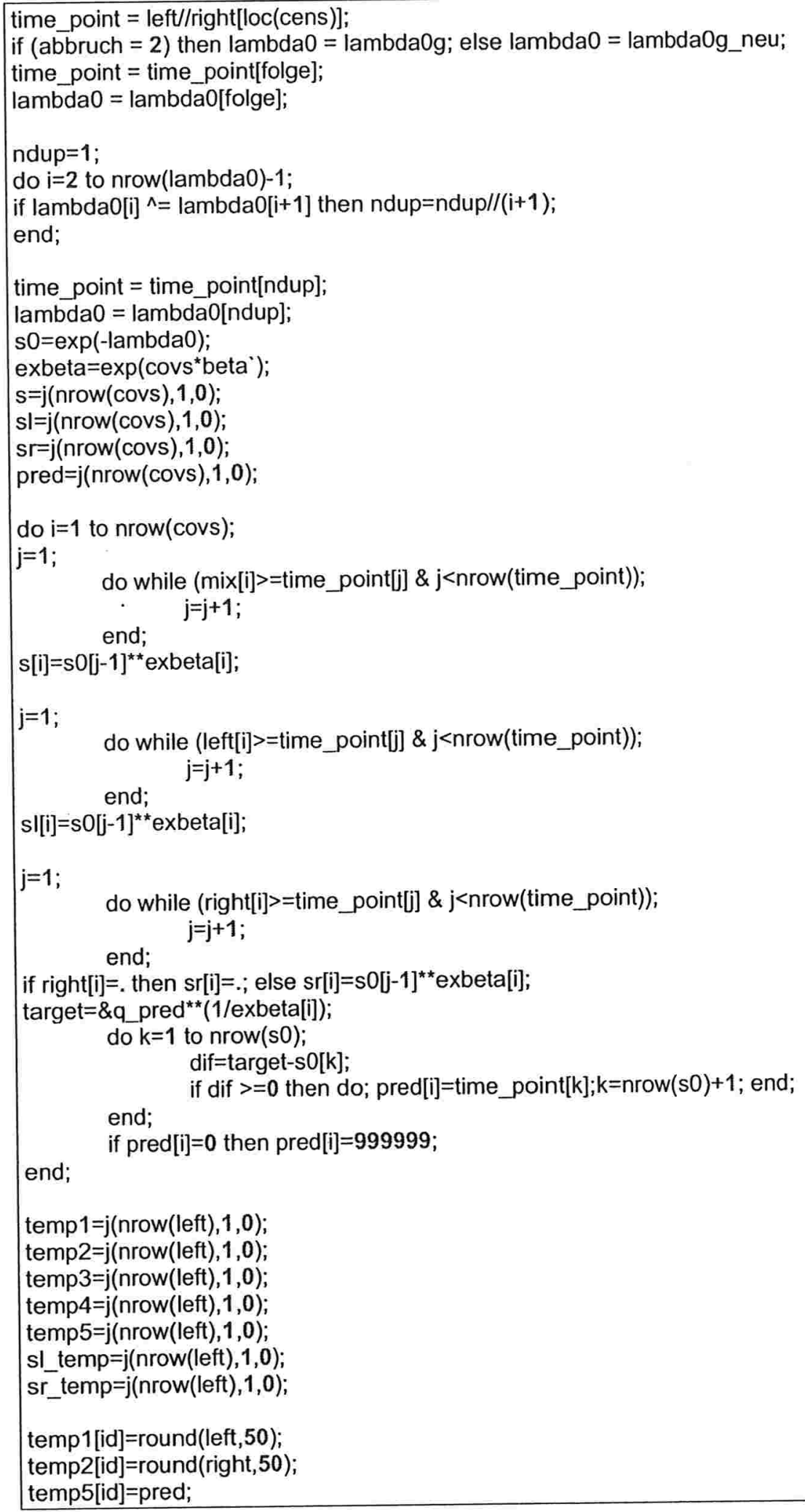


sl_temp[id]=sl;

sr_temp[id]=sr;

beta=beta;

print "verossimilhança $=$ " likeli;

print "interacoes $=$ " it;

print abbruch;

print beta;

print timepoint lambda0;

create \&saida var\{temp1 temp2 temp5 sl_temp sr_temp\};

append ;

quit;

data \&saida;

set \&saida;

rename temp1=left temp2=right temp5=pred sl_temp=s_left sr_temp=s_right;

run;

$\%$ mend;

A macro ICE utilizada para estimação não-paramétrica pode ser encontrada na biblioteca de amostras (SAS Samples Library) do SAS/IML versão 6.11 ou porterior. Essa macro utiliza procedimentos gerados pelas macros no arquivo XMACRO.SAS também disponivel nos diretórios de amostra do SAS. Esses arquivos também podem ser obtidos através da página do SAS na internet (http://www.sas.com) 


\section{Referências bibliográficas}

Alioum, A. \& Commenges, D. (1996). A proportional hazards model for arbitrarily censored and truncated data. Biometrics, 52, 512-524.

Amemiya, T. (1973). Regression analysis when the dependent variable is truncated normal. Econometrica, 41 (6), 997-1016.

Andersen, P.K., Borgan, .Ø, Gill, R. D. \& Keiding, N. (1993). Statistical models based on counting processes. New York: Springer-Verlag.

Aragon, J. \& Eberly, D. (1992). On convergence of convex minorant algorithm for distribution estimation with interval-censored data. Journal of Computational and Graphical Statistics, 1, 129-140.

Bertsekas, D. P. (1982). Projected newton methods for optimization problem with simple constraints. SIAM Journal of Control and Optimization, 20, 221-246.

Chang, M. N. (1990). Weak convergence of a self-consistent estimator of the survival function with doubly censored data. The Annals of Statistics, 18, 391-404.

Collet, D. (1994). Modelling survival data in medical research. London: Chapman and Hall.

Cox, D. R. \& Snell, E. J. (1968). A general definition of residual. Journal of the Royal Statistical Society, Series B, 30, 248-275.

Cox, D.R. (1972). Regression models and life-tables (with discussion). Journal of the Royal Statistical Society, Series B, 34, $187-220$. 
De Gruttola, V. \& Lagakos, S. W. (1989). Analysis of doubly-censored survival data, with application to AIDS. Biometrics, 45, 1-11.

Dempster, A. P., Laird, N. M. \& Rubim, D. B. (1977). Maximum likelihood from incomplete data via the EM algorithm. Journal of the Royal Statistical Society, Series B, 39, 1-38.

Efron, B. \& Tibshirani, R. J (1993). An introduction to the bootstrap. London, U.K.: Chapman \& Hall.

Farrington, C. P. (2000). Residuals for proportional hazards models with intervalcensored survival data. Biometrics, 56, 473-482.

Finkelstein, D. M. (1986). A proportional hazards model for interval-censored failure time data. Biometrics, 42, 845-854.

Fisher L.D \& Lin D.Y. (1999). Time-dependent covariates in the Cox proportionalhazards regression model. Annual Review of Public Health, 20,145-157.

Franses, P. H. \& Paap, R. (2001). Quantitative models in marketing research. Cambridge University Press.

Groeneboom, P. \& Wellner, J. A. (1992). Information bounds and nonparametric maximum likelihood estimation. Basel: Birhauser Verlag.

Hand, D. J. \& Henley, D. J. (1997). Statistical classifications methods in consumer credit scoring: a review". Journal of the Royal Statistical Society, Series A, 160, part 3, 523-541.

Henley, W. E. (1995). Statistical aspects of credit scoring. PhD Thesis. The Open University, Milton Keynes.

Hoper, M. A. \& Lewis, E. M. (1992). Behaviour scoring and adaptative control systems. In Credit Scoring and Credit Control, ed L. C. Thomas, J. N. Crook, D. B. Edelman, Claredon Press: Oxford. 
Huang, J. (1996). Efficient estimation for the cox model with interval censoring. The Annals of Statistics, 24, 540-568.

Huang, J. \& Wellner, J. A. (1995). Efficient estimation for the proportional hazards model with 'Case 2' interval censoring" Technical Report, Univ. of Washington, Dept. of Statistics.

Huang, J. \& Wellner, J. A. (1997). Interval censored survival data: a review of recent progress: in Proceedings of the First Seattle Symposium in Biostatistics: Survival Analysis, New York: Springer, 123-169.

Hyde, J. (1980). Survival analysis with incomplete observations. In Biostatistics Casebook, R. G. Miller, B. Efron, B. W. Brown, and L. E. Moses, eds. New York: John Wiley and Sons, 31-46.

Jongbloed, G. (1998). The iterative convex minorant algorithm for nonparametric estimation. Journal of Computational and Graphical Statistics, 7, 310-321.

Kalbfleisch, J.D. \& Prentice, R.L. (1980). The statistical analysis of failure time data, New York: John Wiley \& Sons, Inc.

Kaplan, E.L. \& Meier, P. (1958). Non-parametric estimation from incomplete observations. Journal of American Statistical Association, 53, 457-481.

Kim, J. S. (2003). Efficient estimation for the proportional hazards model with lefttruncated and 'case 1 ' interval-censored data. Statistica Sinica, 13, 519-537.

Klein, J. P. \& Moeschberger, M. L. (1997). Survival analysis: techniques for censored and truncated data. Springer: New York.

Lagakos, S. W., Barraj, L. M. \& Degruttola, V. (1988). Nonparametric analysis of truncated survival data, with application to AIDS. Biometrika, 75, 515-523.

Lawless, J.F. (2003). Statistical models and methods for lifetime data, 2nd edition. John Wiley and Sons, Hoboken. 
Lima, A. C. P. (1988). Estimação em modelos de Sobrevivência. Dissertação de Mestrado. Insituto de Matemática e Estatística, Universidade de São Paulo.

Lindsey, J. C. \& Ryan, L.M. (1998). Tutorial in biostatistics: methods for intervalcensored data. Statistics in Medicine, 17, 219-238.

Mangasarian, O. L. (1996). Algorithms of nonlinear mathematical programming. CS730 Course Notes, University of Wisconsin, Computer Sciences Departament.

Oliver, R. M. (1993). Effects of calibrations and discrination on profitability scoring. in Proceedings of Credit Scoring and Credit Control III, Credit Research Centre, University of Edinburgh.

Pan, W. (1999). Algorithm for the Cox proportional hazard model for interval censored data. Journal of Computacional and Graphical Statistics, 78, 109-120.

Pan, W. \& Chapell, R. (1998). Computations of the NPMLE of distribution functions for interval censored and truncated data with applications to the Cox model. Computational Statistics and Data Analysis, 17, 33-50.

Robertson, T., Wrigth, F. T. \& Dykstra, R. L. (1998). Order restricted statistical inference. New York: Wiley.

SAS Institute. (1999). SAS/IML User's guide Version 8.2, Cary, NC: Author.

Schoenfeld, D. (1982). Partial residuals for the proportional hazards regression model. Biometrika, 69, 239-241.

Siannis, F. (2004). Applications of a parametric model for informative censoring. Biometrics, 60, 704-714.

Stepanova, M. \& Thomas, L . (2000). Survival analysis methods for personal loan data. School of Management University of Southampton UK.

Therneau, T. M., Grambsch, P.M. \& Fleming, T. R. (1990). Martigale -based residuals for survival models. Biometrika, 77, 147-160. 
Thomas, L. C. (2002). Workshop on new developments in credit scoring methodologies. School of Management University of Southampton UK.

Thomas, L. C., Edelman, D. B. \& Crook, J. N. (2002). Credit scoring and its applications. Siam: Philadelphia.

Tsai, H. T. \& Yeh, H. C. (1999). A two-stage screening procedure for mailing credit assessment. IMA Journal of Mathematics Applied in Business and Industry, 10, 317-329.

Turnbull, B. W. (1976). The empirical distribution function with arbitrarily group, censored and truncated data. Journal of the Royal Statistical Society, Series B, 38 , $290-295$.

Wasserman, G. S. (2003). Reliability verification, testing, and analysis in Engineering Design. Marcel Dekker:Nem York.

Wellner, J. A. \& Zhan, Y. (1997). A Hybrid algorithm for computation of the nonparametric maximum likelihood estimator from censored data. Journal of American Statistical Association, 92, 945-959.

Wooldridge, J. N. (2002). Econometric analysis of cross section and panel data. MIT Press.

Wu, J. F. (1983). On convergence properties of the EM algorithm. Annals of Statistics, 11, 95-103. 